\title{
DE NACIÓN A IMPERIO: LA EXPANSIÓN DE LOS ESTADOS UNIDOS POR EL PACÍFICO DURANTE LA GUERRA HISPANO-NORTEAMERY- CANA DE 1898 ?
}

\author{
por

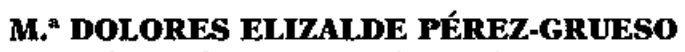 \\ Centro de Estudios Históricos (C.S.I.C.)
}

RESUMEN: La guerra hispano-norteamericana significó para Estados Unidos la adopción de una nueva política internacional, una mayor implicación en la escena mundial y la consolidación de sus intereses en el Caribe, en el Pacífico y en el Extremo Oriente. En este articulo se analizan los condicionantes internacionales en los que se enmarcó la guerra. Se estudia la política exterior de William McKinley, resaltando los distintos factores de carácter político, económico e ideológico que, en 1898, impulsaron a Estados Unidos a la expansión más allá de sus fronteras continentales. Se relaciona la guerra en Cuba con la guerra en Filipinas. $Y$ se dedica una atención especial a la dimensión oriental del conflicto, deteniéndose en tres cuestiones: el ataque de Dewey a Manila, la consolidación de la victoria y la anexión final de las Filipinas.
Palabras clave, 1898, Estados Unidos, Guerra Hispano-Norteamericana, William Mckinley, Política Exterior Norteamericana, Filiplnas, Relaciones Internacionales en el Pacifico.

ABSTRACT: 1898 was the year of the Spanish-American War. For the United States that date has remain as the symbol of the beginning of their transformation from nation to empire. The war with Spain was the moment to adopt a new foreign policy. It supposed a bigger implication in the international scene and the consolidation of the U.S. interests in the Caribbean, in the Pacific and in the Far East. This process had a fundamental importance in the international history of the 20 th century. The paper analyzes the internatio-

1 Este articulo se enmarca dentro de las investigaciones desarrolladas en el Proyecto «El contexto internacional del 98 español", financiado por la Dirección General de Investigación Cientifica y Técnica, núm. PS9/-0003. La autora quiere expresar su agradecimiento a Lorenzo Delgado Gómez-Escalonilla por su colaboración durante la realización de este trabajo. 
nal framework of the Spanish-American War. It studies the foreign policy of William McKinley and the politic, economic and ideological factors which urged to the expansion outside their continental frontiers. It connects the war in Cuba with war in Philippines, and devotes an special attention to three questions in debate: the Dewey attack to Manila, the consolidation of the victory and the annexation of the Philippines.

KEY wORDS: 1898, United States, Spanish-American War, William Mckinley, U.S. Foreign Policy, Philippines Islands, International Relations in the Pacific.

\section{EL MARCO INTERPRETATIVO}

1898 fue el año de la guerra hispano-norteamericana. Para Estados Unidos la fecha ha quedado como el símbolo del inicio de su transformación de nación en imperio ${ }^{2}$. Distintos factores de carácter político, económico e ideológico impulsaron a la nación a la expansión más allá de sus fronteras continentales. El conflicto contra España supuso la adopción de una nueva política internacional, que conllevó una mayor implicación en la escena mundial y la consolidación de los intereses norteamericanos en el Caribe, en el Pacífico y en el Extremo Oriente. Este proceso tuvo una importancia fundamental tanto en su época como en la historia internacional del siglo xx. En este artículo se dará cuenta de los primeros resultados de una investigación en curso sobre la expansión norteamericana por el Pacífico en 1898, sus causas y consecuencias, las reacciones internacionales que provocó y el contexto en que se enmarcó.

Durante muchos años, las interpretaciones sobre la expansión norteamericana por el Pacífico han estado mediatizadas por una serie de presupuestos historiográficos. La historiografía española consideró a la guerra hispanonorteamericana como el "Desastre», un problema privativo de la historia nacional. Era una mirada introvertida de lo ocurrido: desde España y con planteamientos casticistas que tendían a olvidar el contexto internacional en que ocurrió. En los años sesenta, los historiadores españoles comenzaron a dar una nueva importancia a los factores externos y a situar al 98 español en el marco de la expansión colonial ${ }^{3}$. Sin embargo, siguiendo una tradición historiográfica iniciada desde el momento mismo de los hechos por protagonistas como O'Donnell (1902) o por autores coetáneos como Jose M. ${ }^{\circledR}$ Labra

2 Proceso inverso al vivido por España con la pérdida de sus colonias americanas, tal como ha explicado Leandro Prados en su conocido libro De imperio a nación. Crecimiento y atraso económico en España, 1780-1930, Madrid, Alianza Editorial, 1988.

3 Impulsados, entre otros factores -entre los que cabe destacar el mayor aperturismo e interes por «lo exterion» que se iniciaba en España en aquellos años--, por la publicación de la obra de Jesús Pabón; «El 98, acontecimiento internacional», Madrid, Ministerio de Asuntos Exteriores, 1952, reproducido en Dias de Ayer, Barcelona, Alpha, 1963, págs. 139-195.

Hisp̧anid, LVII/2, núm, 196 (1997) 551-588 
$(1900)^{4}$, la atención se centró fundamentalmente sobre los acontecimientos en el Caribe o sobre circunstancias referidas al ámbito europeo, con una doble perspectiva: el análisis de las relaciones de España con las potencias europeas durante la guerra, enfatizando el hecho de que las naciones europeas no respondieron a las peticiones de ayuda del Gobierno español, por lo que España se quedó sola frente a las amenazas norteamericanas. En segundo lugar, la influencia atribuida a Gran Bretaña en las decisiones tomadas por el Gobierno norteamericano durante el conflicto ${ }^{5}$.

Los historiadores españoles seguían sin abordar dos de las principales claves del problema. Primero, un análisis en profundidad de los Estados Unidos en 1898 y en especial de las razones por las que fueron a la guerra con España, explicadas en un contexto general. Segundo, los intereses norteamericanos en el Pacífico y las causas por las que el conflicto hispano-norteamericano adquirío una dimensión oriental. En concreto, la pérdida de los archipiélagos del Pacífico se contemplaba como un apéndice final de la guerra. No se le dedicaban más que unas breves líneas en las que, sin una análisis de las causas ni del proceso, se exponía la cesión y venta de las islas a modo de conclusión del conflicto ${ }^{6}$.

4 O'DonNell y ABreu, Carlos, Duque de Tetuan: Apuntes del Ex-Ministro de Estado para la defensa de la política internacional y gestión diplomática del Gobierno liberal-conservador desde el 28 de Marzo de 1895 al 29 de Septiembre de 1897, Madrid, Tip. y Lit. de Raoul Péaut, 1902, 2 vols. FIGUEROA Y TORRES, Alvaro de, Conde Romanones: Las responsabilidades politicas del Antiguo Régimen, 1875-1923, Madrid, Renacimiento, s.a. LABRA, Rafael Marja de: Estudios de derecho público. Aspecto internacional de la cuestión de Cuba, Madrid, Tipografía de Alfredo Alonso, 1900. Montero Ríos: El Tratado de París de 1898, Madrid 1899.

5 Álvarez GUTIERREZ, Luis: «La diplomacia alemana ante el conflicto hispano-norteamericano de 1897-1898: Primeras tomas de posición», Hispania, LIV, núm. 186, 1994, 201-266. RoBles MuÑoz, Cristobal: 1898. Diplomacia y opinión, Madrid, Consejo Superior de Investigaciones Científicas, 1991. TORRE, Rosario de la: La neutralidad británica en la guerra hispano-norteamericana, Tesis Doctoral, Madrid, Universidad Complutense, 1985. Inglaterra y España en 1898, Madrid, Eudema, 1989.

6 Entre los autores españoles que han estudiado distintas cuestiones relacionadas con Estados Unidos en 1898, pueden citarse a BERMEOSOLo, Francisco: «La opinión pública norteameticana y la guerra de los Estados Unidos contra Espanta» Revista de Estudios Políticos, núm. 123, 1962, 219 233. CASELLAS, Salvador: "Causas y antecedentes diplomáticos de la guerra hispano-norteamericanan Revista de Ciencias Sociales, 4, núm. 1, 1965, 555-755. Morales LezCano, Víctor: «Ideología y estrategia estadounidense: 1898» Hispania, XXIX, 113, 1969, 610-626. ÑIGUEZ BERNAL, Antonio: «Las relaciones politicas, económicas y culturales entre España y los Estados Unidos en los siglos XIX y XX» Quinto Centenario, 12, 1987, 71-134. Togores SANCHEZ, Luis: «España y la expansión de los Estados Unidos en el Pacífico. De la guerra hispano-americana de 1898 y la pérdida de Filipinas al pleito por Sibutó y Cagayán de Jolón Estudios históricos en Homenaje a los pro. fesores Jose M." Jover Zamora y Vicente Palacio-Atard, Madrid, 1990, Universidad Complutense, I, 655-676. Gonzalez Lopez-Briones, Carmen: «The Indiana Press and the Coming of the SpanishAmerican War, 1895-1898" Atlantis. Revista de la Asociación Española de Estudios Anglo-Norteamericanos, 12, 1990, 165-176. COMPANYS, Julián: España en J898: entre la diplomacia y la guerra, Madrid, Biblioteca Diplomática Española, 1992. RuBı, Javier: Las relaciones diplomáticas entre España y Estados Unidos durante el reinado de Alfonso XII, Madrid, Escuela Diplomática, 1996. 
Jose M. ${ }^{a}$ Jover (1979) fue el primero que subrayó la importancia del ámbito oriental en la guerra hispano-norteamericana. En un estudio que ha sido guía y modelo para muchos historiadores españoles señaló que la venta de los archipiélagos del Pacífico fue en realidad un primer proceso de redistribución colonial pactado entre las grandes potencias y dio nuevas claves para entender la crisis del 98 en un marco internacional ${ }^{7}$. Sin embargo, en su trabajo recogía todavía la idea de que el Gobierno norteamericano se anexionó las Filipinas inducido por el Gobiemo británico. Posteriormente Rosario de la Torre (1989) se interesó por los comportamientos británicos en el Extremo Oriente durante la guerra hispano-nortemericana. Desmentía ya la responsabilidad inglesa en la decisión americana de anexionarse Filipinas y desbrozaba el camino para investigaciones posteriores ${ }^{8}$.

Por lo que respecta a la historiografía norteamericana, ha estado dominada, casi desde principios de siglo y durante varias décadas, por la idea de un Presidente McKinley débil, duditativo y sobrepasado por las circunstancias. Arrastrado a una guerra que no quiso por causas en las que no creía. Manipulado por las presiones de diferentes grupos, -económicos, religiosos, expansionistas republicanos, oficiales de marina, o la opinión pública manejada por la prensa- 9 .

En relación con las Filipinas se resaltaba que su adquisición no fue un objetivo bélico, definido con anterioridad al conflicto, sino el resultado de una victoria imprevista. Según esta tesis McKinley se vio obligado a tomar una serie de decisiones que condujeron a la anexión de las islas, en contra de su voluntad, llevado por su sentido del deber con los intereses norteamericanos y con el pueblo filipino. Esta fue la interpretación predominante, mantenida durante décadas en trabajos como los de Julius Pratt (1936), Richard Hofstadter (1952) o Ernest May (1961), por citar sólo tres de los más representativos ${ }^{10}$.

7 JOVER, Jose M.': 1898. Teoría y práctica de la redistribución colonial, Madrid, Fundación Universitaria Española, 1979.

\& Torre, Rosario de la, «En torno al 98. Ingleses y españoles en el Pacifico» En J B. Vilar, ed.: Las Relaciones Internacionales en la España contemporánea, Murcia, 1989, 21 I-222. «Filipinas y el reparto del Extremo Oriente en la crisis de 1898* En El Extremo Oriente Ibérico: Investigaciones y estado de la cuestión, Madrid, CSIC, 1991.

9 Esas interpretaciones historiográficas se acompañaron de una serie de imágenes trasmitidas a lo largo de generaciones. Presentaban al Presidente McKinley paseando noche tras noche por sus aposentos, incapaz de tomar una decisión respecto a las Filipinas, rezando para que le iluminara la Providencia Divina sobre qué debia hacer con los archipiélagos orientales. Otra imágen tópica es la de un McKinley ignorante del Extremo Oriente, del ataque de Dewey sobre las Fillipinas, y de las consecuencias que éste pudiera tener, siguiendo las operaciones de la guerra en un atlas escolar, al hilo de las informaciones que le iban dando sus consejeros. A este respecto se recordaba cómo, cuando un miembro de la Coast and Geodetic Survey fue a darle una detenida charla sobre Filipinas, después de media hora itustrándole, el Presidente le despidió diciendo «es evidente que vamos a aprender mucha geografia en esta guerra». Incluso se extendieron chistes como el que decia: «En qué se parece la cabeza de McKinley a una cama? En que ambas hay que volver a hacerlas todos los dias para poder utilizarlass.

10 PratT, Julius W: «American Business and the Spanish-American War», The Hispanic-American Historical Review, vol. 14, 1934, 163-201. Expansionists of 1898: the Adquisition of Hawaii

Hispumia, LVII/2, núm. 196 (1997) 55i-588 
A fines de los 60, coincidiendo con la apertura de archivos cerrados hasta entonces y con el acceso a fuentes documentales diferentes a la prensa utilizada hasta ese momento, comenzó una profunda revisión de la figura de McKinley, que concluyó con una reivindicación de su talante político. Se replanteó su concepción de la política exterior, su actuación durante la guerra hispano-americana y su responsabilidad en la expansión ultramarina iniciada por los Estados Unidos en 1898. Si bien se discutió la renuecencia de McKinley a entrar en guerra, se subrayó paralelamente su convicción de que Cuba era necesaria para la seguridad y el desarrollo de los Estados Unidos, además de una causa tan popular que la conducta que siguiera el Presidente en esta cuestión influiría, sin duda, en las próximas elecciones presidenciales. Por ello, intentó adquirir la isla por medios pacíficos, pero al percatarse de que no sería posible, na le importó llegar al enfrentamiento armado con tal de conseguir sus objetivos. $Y$ una vez planteada la guerra, fue plenamente consciente de las oportunidades que ésta ofrecía para afirmar la presencia y el comercio americano en Extremo Oriente y hacerse con una serie de islas en el Pacífico. Desde esa posición inició una política claramente expansionista. En esta línea se inscribieron los trabajos de Walter Lafeber (1963), Thomas McCormick (1967), Wayne Morgan (1964), Richard E. Welch (1979), David Trask (1981), John Dobson (1988) o John Offner (1992) ".

Sin embargo, sigue sin existir un consenso entre los historiadores americanos respecto a la anexión final de todas las Filipinas. Esta cuestión está directamente relacionada con el nacimiento del imperialismo norteamericano y por tanto ha sido una causa muy poco popular. Las interpretaciones oscilan entre aquellos autores que afirman que nunca hubo intención de anexionarse ningún territorio en Oriente (Griswold, Dennett, May, Trask); los que sostienen que, una vez producida la victoria de Dewey, se quiso conseguir simplemente una base naval en Manila para potenciar los intereses norteamericanos

and the Spanish Islands, Baltimore, The John Hopkins Press, 1936. America's Colonial Experiment: How the United States Gained, Governed and in Part Gave Away a Colonial Empire, Gloucester, Mass., Peter Smith, 1964. HofstaDTER, Richard: «Manifest Destinity and the Philippines», en America in Crisis, editado por Daniel Aaron, New York, 1952, págs. 188-189. MAY, Ernest R.: Imperial Democracy. The Emergence of America as a Great Power, New York, Harcourt, Brace and World 1961.

11 LAFEBER, Walter: The New Empire: An Interpretation of American Expansion, 1860-1898, Ithaca, Cornel] University Press for the American Historical Assotiation, 1963. McCoRMICK, Thomas: The China Market: America's Quest for Informal Empire, 1893-1901, Chicago, Quadrangle Press, 1967. «The Philippines were insular stepping stones to the Chinese Pot of Gold», en MILLER, Richard: American Imperialism in I898. The quest for National Fulfilment, Nueva York, John Wiley and Sons, 1970. MoRgan, Wayne: America's Road to Empire: The War with Spain and Overseas Expansion, New York, John Wiley \& Sons, 1964. WELCH, Richard E.: Response to Imperialism. The United States and the Philippine-American War, 1899-1902, Chapel Hill, The University of North Carolina Press, 1979. Trask, David: The War with Spain in 1898, New York, MacMillan Publishing Co., 1981. Dobson, John: Reticent Expansionism. The Foreign Policy of William McKinley, Pittsburgh, Pennsylvania, Duquesne University Press, 1988. OfFNer, John: An Unwanted War: The diplomacy of the United States and Spain over Cuba, 1895-1898, Chapel Hill, The University of North Carolina Press, 1992. 
la zona (Dulles, Welch, Offner, Braisted); y quienes subrayan que los fuertes intereses políticos, económicos y religiosos norteamericanos en el Pacífico, y en especial en China, no fueron ajenos al desencadenamiento de la guerra con España (Morgan, Coletta, Lafeber, McCormick, Foner) ${ }^{12}$.

Por su parte, la historiografía británica ha querido, sobre todo, desmentir la tesis planteada en trabajos realizados en lo años veinte y treinta basados en análisis de prensa - Dennis (1928), Mowat (1929), Wilkinson (1932), Gelbert (1938) - - En ellos se asimilaba lo que decían los periódicos de la época con lo que ocurrió en la realidad. Desde esa perspectiva afirmaban que el Gobierno de Salisbury fue el inductor de que McKinley se anexionara las Filipinas ${ }^{13}$.

Frente a esas interpretaciones, trabajos posteriores como los de Neale (1966) y de Grenville (1964), realizados en los años sesenta sobre documentación de archivos, dejaron patente la neutralidad adoptada por el Gobiemo británico en la guerra, al margen de las inclinaciones manifestadas por diferentes sectores de la sociedad británica ${ }^{14}$.

Una segunda línea de esta historiografía ha querido subrayar sobre todo el permanente entendimiento anglo-americano - CS. Campblell (1957), Allen (1954), Perkins (1966)--. Desde esta óptica se destacó que el Gobierno británico mostró una constante deferencia hacia los intereses norteamericanos. Esta interpretación estaba indudablemente influida por los intereses políticos presentes a lo largo de todo el siglo xx de fomentar las relaciones entre Gran Bretaña y Estados Unidos, en lo que se ha llamado la "Special Relationship» 15 .

12 GRISwold, A. Whitney: The Far Eastern Policy of the United States, New Haven, Yale University Press, 1938. DennetT, Tyler: Americans in Eastern Asia. A Critical Study of United States Policy with reference to China, Japan and Korea in the Nineteenth Century, New York, Barnes \& Noble, Inc., 1941. Dulles, Foster Rhea: America in the Pacific. A Century of Expansion, Boston, Houghton Mifflin Company, The Riverside Press Cambridge, 1938. BraISTEd, William R.: The United States Navy in the Pacific, 1897-1909, Austin, University of Texas Press, 1958. ColetTA, Paolo E.: «McKinley, the Peace Negotjations, and the Acquisition of the Philippines» Pacific Historical Review, vol. 30, 341-350. FONER, Philip S.: La guerra hispano-cubano-americana y el nacimiento del imperialismo norteamericano, 1895-1902, Barcelona, Akal Editor, 1972, 2 vols.

13 DenNIs, Alfred: Adventures in American Diplomacy, 1896-1906, New York, Dutton \& Company, 1928. Mowat, R.B.: The Life of Lord Pauncefote, First Ambassador to the United States, London, Constable Co., London, 1929. WILKINSON, Marcus M.: Public Opinion and the Spanish-American War: A study in War Propaganda, Baton Rouge, L. A., 1932. GELBERT, L M.; The rise of Anglo-American Friendship. A study in World Politics, 1898-1906, Oxford University Press, 1938. Este rumor fue recogido por los propios protagonistas de los acontecimientos. Se reflejó en la prensa española y tuvo tal repercusión que el propio embajador británico en Madrid, Drumond Wolff, escribió al subsecretario del Foreign Office, Thomas Sanderson, para confirmar la veracidad tras las noticias que afirmaban que el ministro británico para las colonias, Joseph Chamberlain, había viajado a los Estados Unidos para convencer al Gobierno de McKinley de la conveniencia de la anexión de Filipinas, Public Record Office, F.O. 72/2083, Sanderson to Wolff, 25 Septiembre 1898.

14 Neale, R G.: Great Britain and United States Expansion: 1898-1900, Michigan, State University Press, 1966. Grenville, John A. S.: Lord Salisbury and Foreign Policy. The Close of the Nineteenth Century, London, The Atholone Press, 1964.

15 CAmpblell, Charles S.: Anglo-American Understanding, 1898.1903, Baltimore, The John Hopkins Press, 1957. - From Revolution to Rapprochement: The United States and Great

Hispania, LVII/2, núm. 196 (1997) 551-588 
Un estudio profundo de los fondos documentales británicos demuestra un interés por el flanco oriental de la guerra hispano-norteamericana mayor del que la historiografía ha reconocido. El análisis de la documentación permite afirmar que este asunto fue una preocupación prioritaria para el Gobierno de Salisbury, como evidencian sus continuas gestiones para controlar el posible reparto de los archipiélagos orientales de España y evitar que perjudicara a los intereses británicos en el Extremo Oriente ${ }^{16}$.

Teniendo como referencia el anterior marco historiográfico, esta investigacion se ha basado en las siguientes hipótesis interpretativas. En primer lugar, entendemos que la guerra hispano-norteamericana se debe situar en el contexto internacional de la expansión imperialista de fines del siglo XIX. Más en concreto, en el marco del reparto de territorios y áreas de influencia iniciado en los ultimos años de la centuria por las grandes potencias. Era el momento preciso en que la política internacional, decidida hasta entonces por un grupo limitado de potencias europeas con unos planteamientos eurocentristas, se convertía en política mundial. En ella comenzaban a participar otras naciones, y los espacios extraeuropeos y ultramarinos cobraban una creciente importancia. Proceso que se iría acelerando e incrementando en el devenir del siglo Xx. La nueva política mundial guardaba una estrecha relación con problemas de economía internacional, como la fijación de estrictas políticas arancelarias, el fin de la libertad de mercado y la protección de inversiones en determinadas áreas. En ese contexto fue determinante la decisión norteamericana de no quedar fuera de esa política mundial y en especial del reparto de dos áreas que consideró de interés prioritario: Latinoamérica y el Caribe, donde su posición estaba más o menos consolidada; y el Pacífico, donde, por el contrario, sus intereses peligraban ante las ambiciones de las demás potencias. A nuestro juicio, la iniciativa respecto a extender el conflicto con España al área oriental residió en Estados Unidos. Por ello hemos creído necesario acercamos a los objetivos planteados en esta investigación desde la perspectiva norteamericana, para posteriormente completarla con otros enfoques. No se debe olvidar que en el desarrollo del proceso influyó directamente la actitud de las demás naciones y en particular sus intereses ante el futuro de los archipiélagos españoles del Pacífico. Junto a lo anterior hay que considerar también la actitud del Gobierno español: salvar contra toda razón las islas que pudiera. En este empeño, y a pesar de los muchos esfuerzos y gestiones, tuvo un escasísimo margen de maniobra. El futuro de sus colonias se resolvió en un tablero internacional en el que los triunfos estuvieron en manos ajenas.

Britain, 1783-1900, New York, John Wiley, 1974. - The Transformation of American Foreign Relations, 1865-1900, New York, 1976. ALLEN, H C.: Great Britain and the United States. A History of Anglo-American Relations, 1783-1952, London, Odham Press Limited, 1954. PERKINs, Bradford: The Great Rapprochement: England and the United States, 1895-1914, New York, 1968.

16 Public Record Office, Foreign Office, fondos correspondientes a General Correspondence, Embassy and Consular Archives, Confidential Prints y Treaties del año 1898, cruzados entre Gran Bretaña y los siguientes países: España, Estados Unidos, Alemania, Francia, Rusia y Japón. 
Finalmente, en el planteamiento de la crisis hispano-norteamericana en el Pacífico hubo una directa implicación de los pueblos dominados por España. Las luchas nacionales de liberación que se iniciaban entonces en Filipinas y en Carolinas fueron utilizadas por los americanos para intervenir en aquellos archipiélagos, de la misma manera que lo hicieron en Cuba. Para comprender mejor el marco en el que se insertó la crisis de 1898 vamos a revisar a continuación más detenidamente los condicionantes internacionales.

\section{LOS CONDICIONANTES INTERNACIONALES}

La historiografía española ha orientado el análisis de la crisis de 1898 desde una óptica fundamentalmente nacionalista. Si bien es cierto que el 98 no provocó a corto plazo una crisis de estado ni una ruptura institucional y que el Régimen de la Restauración demostró una alta capacidad de recuperación. Si aceptamos que la economía española no se resintió gravemente y que por contra factores como la repatriación de capitales, la caída de la peseta que fomentó un auge de las exportaciones, la continuación de los negocios e inversiones en las antiguas colonias o el saneamiento económico llevado a cabo por Francisco Silvela, potenciaron el crecimiento de la economía ${ }^{17}$. Paralelamente a todo ello, tendremos que subrayar que el 98 tuvo una serie de repercusiones fundamentales en diferentes campos de la vida española: el desprestigio del sistema político de la Restauración acabaría por pasar factura varias décadas más tarde; se intensificaron las movilizaciones populares y el resentimiento contra la clase política en el ejercicio del poder; se produjo un replanteamiento del proyecto nacional; se extendieron nuevas propuestas ideológicas y las asociaciones obreras de distinto signo adquirieron un nuevo auge; los movimientos nacionalistas cobraron fuerza; se cuestionó el papel del ejército dentro del estado; el mundo intelectual reaccionó frente al ambiente de crisis nacional intensificando sus propuestas para regenerar el país; se fomentó un espíritu de renovación que impulsó reformas sociales, educativas, sanitarias, de obras públicas ${ }^{18}$.

Sin embargo, antes que todo eso, que al fin y al cabo son las repercusiones del 98 en la sociedad española, hay que pensar qué fue el 98 . Desde nuestro punto de vista el 98 fue ante todo el fin del imperio español, la pérdida de Cuba, Puerto Rico, Filipinas y los archipiélagos de la Micronesia. Lo cual significó el ocaso de la presencia de España en la escena internacional como potencia con soberanía sobre territorios ultramarinos repartidos por todo el mundo. Porque

\footnotetext{
17 Especialmente interesantes para este tema son los trabajos realizados por Jose M. Serrano, Jordi Maluquer de Motes, Josep M.' Fradera, Josep M. Delgado, Leandro Prados, Pablo Martín Acer̃a y Francisco Comín.

is Sobre esta cuestión han trabajado Sebastian Balfour, Juan Pablo Fusi y José Alvarez Junco, que expusieron sus conclusiones al respecto en el Seminario «Nuevas interpretaciones sobre la crisis española de 1898», celebrado por el Dpto. de Historia Contemporánea dentro del Congreso “ $\$ 898$ ¿ruptura o continuidad?» organizado por el Centro de Estudios Históricos del CSIC en Octubre de 1996.

Hispania, LVI1/2, núm. 196 (1997) 551-588
} 
aunque luego se potenciara otro pequeño imperio en Africa y los ímpetus de los sectores colonialistas españoles se trasladaran a este nuevo escenario, las colonias africanas ya poco tendrían que ver con el viejo imperio español. El 98 fue también un problema internacional de primer orden. En esa fecha, y con ocasión de la guerra hispano-norteamericana, se pusieron en cuestión los territorios ultramarinos de España y se abrió un debate internacional sobre el futuro de esos enclaves, en el cual participaron las principales potencias del momento.

La pregunta fundamental sería por qué ocurrió el 98 , por qué se perdieron aquellas antiguas colonias españolas. En este punto podría hablarse de una política colonial equivocada, de unas medidas económicas cuestionables que alejaron a las colonias de la metrópoli - aunque no la viceversa- ${ }^{19}$. Habría que señalar también la importancia de los movimientos separatistas en Cuba y en Filipinas. Eran estos problemas importantes, diferentes unos de otros, aunque intrínsicamente unidos, que probablemente hubieran provocado a la larga el mismo resultado: la independencia de las colonias españolas en las Antillas y en el Pacífico. Pero este proceso hubiera podido producirse de otra manera y en otro momento, con otros procedimientos, quizás menos traumáticos para la sociedad española, sin injerencias extrañas y exteriores a los propios interesados. Si la pérdida de las colonias se produjo en 1898 y como consecuencia de la guerra hispano-norteamericana, en un enfrentamiento con Estados Unidos en el Caribe y en el Pacífico, fue precisamente por razones que se derivaron del marco internacional.

El sistema internacional en el que se insertó la crisis de 1898 estaba caracterizado por una serie de condicionantes. El primero de ellos sería, sin duda, el imperialismo. Era la época en la que las relaciones entre las naciones se basaban fundamentalmente en la fuerza, el potencial económico, la capacidad militar. Atrás quedaban el concierto europeo y el equilibrio acordado. Aún no habían llegado los tiempos de la seguridad colectiva, los esfuerzos conjuntos para mantener la paz. En aquellos tensos años de fin de siglo primaba la razón del más fuerte, los actos de fuerza del más poderoso a los que nadie se atrevía a oponerse. Era también el momento de la máxima expansión colonial, en el que las potencias se estaban repartiendo los últimos territorios libres y comenzaban a plantear temas que hasta el momento habían permanecido cerrados: el reparto de China; el status de aquellos territorios que estaban bajo soberanía de antiguas potencias coloniales, pero sobre los cuales éstas apenas tenfan ya control ni fuerza para defenderlos; la resolución y adjudicación de áreas que habían permanecido en un difícil estado de equilibrio entre intereses enfrentados, caso de Samoa; pronto se abriría el problema del norte de Africa y se lucharía por el dominio del Mediterráneo. En ese contexto, además de una fuente de beneficios económicos, las colonias se consi-

19 Entre los pocos análisis teóricos sobre la política colonial española en el siglo xix pueden citarse los trabajos de Josep M. Fradera, Elena Hernandez Sandoica, Antonio Elorza, Jose Antonio Piqueras o Candelaria Sanz Pastor. Tema que también puede entreverse en muchos de los estudios que Jose Maria Jover ha dedicado al ultrarnar español.

Hispania, LVI1/2, nủı. 196 (1997) 551-588 
deraban como un atributo de la fuerza estatal, la demostración de la vitalidad nacional. Para ser gran potencia había que tener colonias: eran muestra de grandeza y daban idea del prestigio internacional de una nación. La intervención de Estados Unidos en los problemas entre España y sus colonias, su posterior incorporación de varias de esas islas y el evidente interés de otros países por hacerse con alguno de los territorios españoles puestos en cuestión, se insertó en este marco de expansión imperialista de las grandes potencias, de lucha por territorios con un especial interés político, económico o estratégico.

Unido a este auge del imperialismo hay que subrayar la relevancia que en los últimos años del siglo XIX adquirieron los espacios extraeuropeos. No como ámbitos lejanos y ajenos, sino como espacios íntimamente ligados con lo que ocurría en el resto del mundo, evidenciando una situación de estrecha relación entre centro y periferia y una clara repercusión entre las alianzas, intereses y conflictos en Europa y en estos ámbitos extraeuropeos. En este contexto hay que destacar la nueva importancia del Pacífico, del Extremo Oriente en general y de China en particular, dentro de las relaciones internacionales y de la expansión colonial. En este área seguía existiendo una hegemonía británica, pero se estaba produciendo una progresiva penetración de Alemania, Francia y Rusia. En los primeros meses de 1898 pareció incluso que iba a iniciarse un reparto de China y del Pacífico por zonas de influencia. En este ámbito irrumpieron dos nuevas potencias mundiales - Estados Unidos y Japón-, que cobraron una nueva importancia en el juego de alianzas internacionales y mostraron unos claros intereses expansionistas.

Otros rasgos del sistema internacional de la época, muy directamente relacionados con lo anterior, vendrían determinados por problemas de economía internacional, como podían ser la adopción de políticas arancelarias proteccionistas, el establecimiento de mercados privilegiados, la concesión de préstamos, la construcción de ferrocarriles o el establecimiento y control de líneas de comunicación con las colonias; problemas todos ellos que afectaban e interesaban a los países con ambiciones expansionistas.

Hay que resaltar también, como clave fundamental para entender el marco internacional en el que se insertó la crisis de 1898, el alto grado de desarrollo alcanzado por los Estados Unidos. A fines del siglo XIX los Estados Unidos habían conseguido una vertebración nacional. Habian llegado al límite de sus fronteras subcontinentales. Habían desarrollado su industria y su economía hasta convertirse en uno de los países económicamente más poderosos. Estas circunstancias favorecieron la propagación de corrientes de opinión que reclamaron el desempeño del papel que como gran potencia les correspondía en la escena internacional. A este tema vamos a dirigir nuestra atención a lo largo de este artículo.

\section{LA POLITICA INTERNACIONAL. DE WLLIAM MCKINLEY}

En 1898 el Gobierno de los Estados Unidos reafirmó y asumió oficialmente la expansión ultramarina que los norteamericanos habían iniciado 
hacía muchas décadas y que se había ido incrementando con el paso del tiempo, aún sin el respaldo gubernamental. El Presidente McKinley adoptó una nueva política exterior, intensificando la implicación norteamericana en la escena internacional. En este proceso la guerra hispano-norteamericana marcó un hito en la transformación de los Estados Unidos de nación en imperio, porque supuso la anexión de territorios extracontinentales, cuya soberanía pasó a depender del Gobierno de Washington, que desde entonces ejerció un nuevo poder político sobre ellos ${ }^{20}$.

\section{Trayectoria política, personalidad y directrices de su Presidencia}

En 1896 fue elegido Presidente de los Estados Unidos el republicano William McKinley. Nacido en Ohio en 1843, tuvo una destacada conducta durante la Guerra de Secesión. Después de la confrontación se hizo abogado, aunque pronto entró en el mundo de la política. En 1876 fue elegido representante de su Estado en el Congreso. Durante las legislaturas que trabajó en esta Cámara se especializó en asuntos económicos en torno a los principios básicos de los republicanos: oposición al libre comercio, apoyo a las tarifas proteccionistas que hicieran crecer la industria y el mercado interno. Al final de este período era uno de los políticos que mejor había entendido la industrialización americana, dominaba el debate sobre política aduanera y conocía bien las necesidades de los poderosos círculos que habían modernizado el campo. En 1890 decidió presentarse a las elecciones para Gobernador de Ohio, cargo para el que fue elegido en 1891. En esta nueva etapa destacó como hábil administrador que supo mantener a su Estado fuera de la depresión que azotaba otras zonas de los Estados Unidos. En 1896, apoyado por el Partido Republicano, y en especial por hombres como John Hay, William Day - Mark Hanna, que fue quien financió su campaña presidencial, McKinley ganó las elecciones presidenciales frente a William J. Bryan, un político del Partido Demócrata que gozaba de una gran popularidad ${ }^{21}$.

McKinley fue un Presidente apreciado por sus contemporáneos. Amable, sereno y cortés, personificaba la dignidad tanto en las formas como en el len-

20 «L'année 1898 est généralement considéré comme la date d'un grand tournant dans l'histoire américaine; la guerre contre l'Espagne signale l'arrivée sur la scène mondiale d'une nouvelle puissance impérialiste: les Etats-Unis. Pour leur position dans le Pacifique, il s'agitt effectivement d'un. bond impressionant, puisque leur première ligne, jusqu'alors limitée à la côte ouest passe brutalement aux portes du continent asiatique avec la conquète des Philippines et de Guam, l'annexion de Hawai et de Wake et la partition des Samoas HefFer, Jean: Les Etats-Unis et le Pacifique. Histoire d'une frontiere, Paris, Editions Albin Michel, 1995, pág. 202.

21 OLCort, Charles S.: Life of William McKinley, Boston, Houghton Miffin Company, 1916. LEECH, Margaret: In the Days of McKinley, New York, 1959. MORGAN, Wayne H.: William McKinley and His America, Syracuse, Syracuse University Press, 1963. Gould, Lewis: The Presidency of William McKinley, Lawrence, Regents Press of Kansas, 1980. GoulD., L \& CRAIG, H R.: William McKinley: A Bibliography, Westport, Conn., Meckler, 1988. 
guaje. Fue un devoto cristiano, de hábitos austeros, un puritano escricto que encajaba en la más pura tradición norteamericana, con quien sus conciudadanos se identificaban fácilmente. Se alababa la devoción con que siempre atendió a su esposa, invalida y necesitada de muchos cuidados. Estos rasgos de su carácier hacían que no pareciera la persona más indicada para emprender una política internacional agresiva.

En el terreno político mostró un talante conciliador y receptivo. Extremadamente prudente en todas sus manifestaciones, prefería evitar los enfrentamientos abiertos. Era intencionadamente ambiguo. No hacía declaraciones tajantes de sus propósitos, sino que resolvía las cuestiones con paciencia, hasta conseguir convencer a su entorno, e incluso a sus adversarios, de que la política que iba a seguir, nunca confesada con demasiada antelación, era la mejor opción posible. Por eso se le ha achacado ser un hábil manipulador de la opinión pública. Tardaba en tomar las decisiones y actuaba sólo cuando había conseguido los apoyos necesarios para que su causa prosperase y fuera popular. Esta política dilatoria le hizo parecer a veces débil e indeciso, pero en el fondo demostró ser un astuto negociador, que ejecutó con firmeza las acciones que previamente había decidido, sin perder por ello una especial facilidad para conectar con el pueblo ${ }^{22}$.

Avalado por estos antecedentes, parecía que McKinley iba a dedicar su atención a resolver los problemas domésticos y en especial a sacar al país de la crisis económica. Había afirmado que daría prioridad a cuestiones como los problemas de tarifas ${ }^{23}$ o la política monetaria frente a otros asuntos inter-

22 Papeles de William McKinley, Biblioteca del Congreso de los Estados Unidos, Washington. Un coetáneo suyo decía de él: «McKinley prefería agradar a desagradar, ayudar a hundir, sonreir a enfrentarse». STOdDARD, Henry: As I knew them, 2 vols, New York, Harper, 1927, l: pág. 230.

23 McKinley había sido el responsable de la Tarifa de 1890, que había fijado unos derechos aduaneros altos. Después de las bajadas efectuadas por Cleveland, especialmente en 1894, al llegar McKinley al Gobierno quiso volver a tradicional política republicana proteccionista, aunque contrartestada por tratados de reciprocidad como fórmula de negociación exterior. Los primeros meses de su presidencia estuvieron dedicados a ja formulación de las nuevas tarifas aduaneras. Los debates estuvieron dirigidos por Nelson Dingley, representante de Maine en el Congreso y de quien el Presidente hubiera deseado que fuera su Secretario del Tesoro. Sin embargo, él prefirió quedarse al frente de la batalla aduanera en el Congreso, tal como el propio McKinley había hecho años atrás. La estrategia de McKinley y Dingley se basaba en negociar posteriores ajustes específicos para determinadas tarifas. El Congreso pareció aceptar sus propuestas, pero el Senado se mostró más reticente y en particular varios de sus miembros se declararon proteccionistas convencidos, no dispuestos a favorecer una rebaja de las tarifas, ni general, ni específica. Tras las pertinentes negociaciones el acta final, ilamada la Dingley Act, fijaba un incremento de las tarifas mayor del que McKinley hubiera deseado para muchos productos. Además, tuvo que aceptar una lista de previsión de reciprocidades menor del que pensaba, lo cual dificultaria las exportaciones que quería fomentar. Esto, indudablemente, afectaria a la política exterior que podría desarrollar, al determinar muy estrechamente, y en numerosos casos dificultar, los intercambios con determinados paises. La Dingley Act incluía fundamentalmente tres tipos de previsiones de reciprocidad. Las dos primeras estaban dedicadas a aquellas potencias que habian discriminado las exportaciones americanas en el pasado. Una de ellas se refería a determinadas naciones europeas y limitaba muy estrictamente los

Hispanite, LVII/2, núis. 196 (1997) 551-588 
nacionales ${ }^{24}$. Impresión que se acrecentaba por no tener una política exterior claramente definida. Durante su campaña había sido poco preciso respecto a lo que iban a ser sus directrices exteriores, indicando únicamente que tendría una política internacional digna y firme. No quería guerras de conquista. Deseaba evitar.las agresiones territoriales. Defendía que el enfrentamiento sólo debía llegar cuando hubieran fallado todas las negociaciones para la paz.

Nada en sus doctrinas políticas, en sus maneras, ni en la trayectoria seguida hasta entonces hacía sospechar que sería el Presidente que iniciaria la construcción de un imperio ultramarino. Sin embargo, el fuerte sentimiento expansionista que se extendió entre importantes sectores de la sociedad americana en la década de 1890, junto a una serie de acontecimientos que se percibieron como amenazas para la seguridad y los intereses norteamericanos, le situaron en una coyuntura en la que tuvo que decidir la entrada en una guerra, la intervención en espacios ultramarinos y la anexión de territorios coloniales.

\section{Sus colaboradores}

En los primeros meses de su mandato, McKinley no tuvo un hombre fuerte como Secretario de Estado, a pesar de que generalmente éste era el miembro del Gobierno con más poder e influencia. Hubiera querido ofrecer este puesto a Mark Hanna, que tanto le había apoyado en la carrera presidencial, pero ambos decidieron que su presencia sería más necesaria en las Cámaras, donde tendría que librar importantes batallas para sacar adelante las propuestas del Presidente. El puesto lo ocupo John Sherman, que había sido Secretario del Tesoro y senador por Ohio durante seis legislaturas - su escaño en el Senado lo cubrió Hanna-. Sherman tenía setenta y cuatro años y una salud delicada.

productos para los que se podían alterar las tarifas proteccionistas. La otra especificaba aquelios productos tropicales que podrían tener tarifas bajas siempre que a cambio los países respectivos bajaran también los aranceles de entrada para los productos importados de los Estados Unidos. La tercera medida autorizaba al Presidente a negociar acuerdos aduaneros que redujeran las tarifas un $20 \%$ a los productos importados de otros países, si éstos rebajaran la misma cantidad a las exportaciones norteamericanas. Todos los acuerdos debian contar con la aprobación de ambas Cámaras y no podían estar en vigor más de cinco años. Claramente, estas medidas no estaban diseñadas para beneficiar las importaciones, sino para que pudieran aumentar las exportaciones americanas en los mercados extranjeros. Sin embargo, al ser tan restrictivas, dejaban un estrecho margen de maniobra para una política comercial expansiva.

24 Uno de los principales problemas aftontados durante su mandato fue el debate en torno a la adopción del patrón oro. McKinley inicialmente era partidario del mantenimiento del bimetalismo y del establecimiento de una tasa de cambio basada en la combinación del oro y la plata. Las conversaciones mantenidas por su Gobierno con los de otros países en relación a este tema, la caída mundial del precio de la plata, el descubrimiento de nuevas reservas de oro en Alaska y unas balanzas comerciales más favorables a los Estados Unidos, le hicieron desistir de su idea anterior e inclinarse por el patrón oro. Su administración impulsó la firma de la Gold Standard Act de 1900, que supuso el final del bimetalismo. 
Se oponía al expansionismo y no deseaba llevar a cabo una política enérgica en el exterior. A pesar de ser la cabeza visible de este Departamento, McKinley desarrolló gran parte de su política exterior sin contar con él.

Conociendo las carencias de Sherman, McKinley nombró como Asistente del Secretario de Estado a William R. Day, un viejo amigo de Ohio, abogado y socio en sus negocios, consejero legal suyo una vez que entró en política. Day hubiera querido dedicarse unicamente a sus tareas como juez y abogado, pero aceptó el cargo por su estrecha amistad con McKinley, que quería un hombre de su entera confianza dentro de la Secretaría de Estado. Fue Day quien realmente respaldó las iniciativas del Presidente en política exterior y quien mantuvo la línea directa entre la Casa Blanca y la Secretaría de Estado. Incluso asistió a las reuniones del Gabinete con mayor asiduidad que Sherman. Finalmente, justo en el momento de estallar el conflicto con España, Day fue nombrado Secretario de Estado el 26 de Abril de 1898. Fue, por tanto, la persona que estuvo junto a McKinley durante los meses de la guerra hispano-nortemericana y quien le apoyó en las decisiones adoptadas. Posteriormente, al entrar a formar parte de la Comisión que negoció en París los términos de la paz con España, fue sustituido en el cargo como Secretario de Estado por John Hay, anteriormente embajador en Londres y buen conocedor de los intereses internacionales en la guerra ${ }^{25}$.

El personal de la Secretaría de Estado consistía en unos sesenta empleados, presididos por Alvey A. Adee, como Segundo Asistente del Secretario de Estado. Era éste un hombre de enorme experiencia en el puesto, un técnico que conocía bien los entresijos de la Casa, en la que había entrado en su juventud y en la que permaneció durante cincuenta y cinco años, hasta su jubilación en 1924. Conocia a fondo las formulaciones de la política exterior norteamericana y como resolver los problemas. Gran parte de los despachos e informes que pasaban por la Secretaría llevaban escritos por su mano observaciones respecto a la cuestión de la que se tratara. Fue un funcionario extraordinariamente hábil y eficiente, que supo manejar con solvencia los asuntos internacionales que se planteraron durante los muchos años en los que ocupó el cargo ${ }^{26}$.

Los otros dos miembros del Gabinete que tuvieron responsabilidades en política exterior fueron los Jefes de los Departamentos del Ejército y de la Marina. McKinley eligí́ a Russell A. Alger como Secretario de Guerra. Había sido general y político en Michigan y fue uno de los miembros del Gobierno más belicosos cuando se planteó el conflicto con España. El Secretario de Marina fue John David Long, ex-gobernador de Massachussets y pacifista convencido. Sin embargo, su política estuvo contrarrestrada por las inciativas

25 Bemis, Samuel Fjagg: The American Secretaries of State and their Diplomacy, New York, Alfred A. Knopp, 1929, Vol IX: John Sherman, by Lousis Martin Sears; William Day by Lester Shippe \& Royal Way; John Hay, by AL. Dennis.

26 PLISCHKE, Elmer; Conduct of American Diplomacy, New York, D. Van Nostrand Company, 1950. PraTt, Julius: A History of United States Foreign Policy, New York, Prentice-Hall, inc., 1955.

Hispania, LV]l/2, núm. 196 (1997) 551-588 
de su asistente, Theodore Roosevelt, firme partidario de la expansión de los Estados Unidos ${ }^{27}$.

Para las embajadas más significativas McKinley nombró a hombres de su entera confianza: John Hay en Londres, Horace Porter en París, Andrew White en Berlín, y Steward Woodford en Madrid, como enviado especial en los meses anteriores al estallido de la guerra con el objeto de que intentara por todos los medios paćficos posibles la renuncia española a Cuba ${ }^{28}$.

\section{Fundamentos para una política expansiva}

Tres tipos de factores influyeron en la política exterior norteamericana de fines del siglo XIx: los político-estratégicos, los económicos y los ideológicos.

Las motivaciones políticas se apreciaban en la insatisfacción que determinados grupos políticos cercanos al Presidente mostraron por la posición que su país ocupaba en la escena internacional, considerándola impropia de su verdadera condición. A fines del siglo XIX los Estados Unidos habían culminado la consolidación de su nación, habían conseguido la vertebración nacional -aún persistiendo, como es lógico, numerosos problemas de política interna-. Su econornía había alcanzado un alto grado de desarrollo. Su producción industrial era mayor que la de ningún otro país. Su balanza comercial favorable. Eran el estado más poblado después de Rusia. Tenían los medios técnicos y los instrumentos necesarios para afirmar su posición e impulsar una política exterior expansiva.

Una parte importante de la sociedad norteamericana pensaba que estos hechos debían reportarles un merecido respeto internacional y un puesto relevante entre las grandes potencias. Por ello expresaron su deseo de demostrar el poderío de su nación, su potencial económico y sus avances militares a través de la participación en la política mundial y en la expansión ultramarina. McKinley no se encontraba entre la élite que defendió publicamente esas ideas, pero recibió la influencia de estos sectores a través de colaboradores muy cercanos: políticos de su partido, como Henry Cabot Lodge ${ }^{29}$ y

27 ALGER, Russell: The Spanish-American War, New York, Harper and Brothers, 1901. LoNG, John Davis: The Journal of John D. Long, edited by Margaret Long, Ridge, N. H., Richard Smith, 1956. Roosevelt, Theodore: An Autobiography, New York, Macmillan, 1919. Bishop, B.: Theodore Roosevelt and His Time, New York, 1920.

28 Dennett, Tyler: John Hay, Front Poetry to Politics, New York, Dodd, Mead\&Company, 1934. Clymer, K J.: John Hay, The Gentleman as Diplomal, Ann Arbor, The University of Michjgan Press, 1975. White, Andrew: Aotobiography, New York, Century, 1905. Sobre la embajada de Steward Woodford en Madrid: CompanYs MonCLus, Julián: España en 1898: entre la diplomacia y la guerra, Madrid, Biblioteca Diplomática Española, 1992.

${ }_{29}$ «En el interés de nuestro comercio y de nuestro futuro desarrollo deberíamos unir Canadá a la Unión, construir el canal de Nicaragua; para la protección de ese canal y para asegurar nuestra supremacía comercial en el Pacífico deberíamos controlar las islas Hawai y mantener nuestra influencia en Samoa... y cuando el Canal esté construido, Cuba será para nosotros una necesidad», 
Theodore Roosevelt ${ }^{30}$; estrategas como Alfred Mahan ${ }^{31}$; o intelectuales como Brooks Adams. Todos ellos le insistieron en la necesidad de lo que se llamó la «large policy», en merced de la cual los Estados Unidos debían de extender progresivamente su influencia por el mundo hasta alcanzar el puesto que les correpondía en la escena internacional. Para afirmar esa posición los Estados Unidos debían contar con un ejército y en especial una marina capaces de asegurar la defensa de los territorios norteamericanos; con medios propios que aseguraran sus comunicaciones; con estaciones carboneras estratégicamente situadas; con líneas de cable bajo su controf; y con un perímetro defensivo que garantizara la seguridad nacional, en el cual tendrían que incluirse puntos tan significativos como el canal interoceánico, Cuba y Hawai ${ }^{32}$.

El segundo grupo de motivos que influyeron en el diseño de la política exterior fueron los económicos. Importantes grupos de negocios subrayaron la necesidad de nuevos mercados donde vender los excedentes de la producción agrícola e industrial y nuevas áreas para la inversión de capitales. Por ello solicitaron la expansión más allá de sus fronteras, señalando en particu-

LODGE, Henry Cabot: «Our Blundering Foreign Policy», Forum, 19 Marzo 1895, págs. 16-17. Tres días después de la victoria de Dewey, Lodge declaraba a White que no debían permitir que las islas se fueran de sus manos, ahora que tenian el otro lado del Pacífico, cuyo valor para la nación estaba más allá de todaa consideración. Al poco tiempo escribia a Roosevelt: «All proper means were to be taken to secure both the Philippines and Porto Rico... I have every reason to believe that the Administration is now fully committed to the large policy that we both desire» Lodge to Roosevelt, 24 May 1898, LoDGE, Henry C., ed: Selections from the Correspondence of Theodore Roosevelt and Henry Cabot Lodge, 1884-1918, New York, 1925, 1, págs.299-300.

${ }^{30}$ Roosevelt to Lodge, 4 Diciembre 1896: «l do hope he (McKinley) will take a stong stang both about Hawaii and Cubaw; Roosevelt to Lodge, 27 Octubre 1897: I do wish our Republican would go in avowedly Hawaii and build an oceanic canal with the money of Uncle Samm; Roosevelt to Mahan: «I have getting matters in shape on the Pacific Coast...If I had my way, we would annex those islands tomorrow... w would hoist our flag over the island leaving the details for after actions. LODGE, Henry C., ed: Selections from the Correspondence of Theodore Roosevelt and Henry Cabot Lodge, 1884-1918, New York, 1925, 1, págs. 139. 243.

31 MAHAN, Alfred T: The Influence of Sea Power Upon History, Boston, 1890.

32 PratT, Julius W.: «The Large Policy of 1898» The Mississippi Valley Historical Review, vol. $19,1932,219-242$. En este articulo Pratt va examinando distintos episodios ocurridos en la década precedente a la guerra hispano-norteamericana, poniendo de relieve la existencia de una corriente de opinión que desde entonces deseaba la expansión de los Estados Unidos por el Caribe, el Pacifico y el Extremo Oriente, y resaltando textos en los que autores de muy distinta procedencia instaban a la adpoción de tal politica. «That a large policy was in the air was no secret to any one who had read attentively American periodical literature or the pages of the Congressional Record during the preceding decade...The large policy of the leading representatives of this new spirit, Roosevelt and Lodge, aimed at no less than making the United States the indisputably dominant power in the western hemisphere, possessed of a great navy, owning and controlling an Isthmian canal, holding naval bases in the Caribbean and the Pacific, and contesting, on at least even terms with the greatest powers, the naval and commercial supremacy of the Pacific Ocean and the Far East. That this was their policy, and that it was shared by many others, wil! become apparent from a glance at certain chapters in American history in the ten years preceding the war with Spain", págs.222-223.

Hi.spania, LVII/2, núm. 196 (1997) 55I-588 
lar dos áreas que aún no estaban totalmente controladas o colonizadas por otros países: Latinoamérica y el Extremo Oriente ${ }^{33}$.

Este es un tema que ha sido muy discutido en la historiografía americana. Se ha recordado que los sectores agrícolas preferían la protección del mercado interior; las reticencias de los banqueros y de los círculos económicos de la costa Este ante una política expansiva; los temores de que ese proceso pudiera detener la recuperación que se observaba tras la crisis de 1893. Hoy en día los economistas discuten también que la expansión hacia ámbitos coloniales fuera la opción más conveniente para el crecimiento de la economía, frente a otras alternativas como invertir e incentivar el comercio con Canadá o con Europa, donde la relación costes-beneficios podía ser más favorable. De hecho, los Estados Unidos mantenían importantes relaciones comerciales con diferentes países europeos, y en particular con Gran Bretaña y Alemania. Sin embargo, nos ha quedado la evidencia de numerosos textos e informes que demuestran que en los primeros meses de 1898, independientemente de lo que pensaran antes, círculos económicos de todo el país, de manera consensuada aunque siempre con disidentes, solicitaron a McKinley la conquista de nuevos mercados en Asia y Latinoamérica, así como la protección de las inversiones en estos espacios ${ }^{34}$.

33 Latinoamérica se presentaba como un mercado cada día más atractivo para tos Estados Unidos en virtud de la doctrina Monroe - enunciada por el Presidente Monroe en 1923 y según la cual el Gobierno norteamericano veria con disgusto cualquier injerencia europea en áreas próximas a su nación o en asuntos que afectaban exclusivamente al continente americano-, que los diferentes Gobiernos americanos del siglo XIX se habían encargado de promover frente a los intereses de las naciones europeas en este continente. Asi, desde mucho antes de que McKinley fuera presidente habían aumentado las inversiones y el tráfico comercial norteamericano con Méjico, América Central y el Caribe. La próximidad de estas áreas y el convencimiento en el predominio de los Estados Unidos en su propio hemisferio animaban a las actividades económicas con los países al sur de su frontera. Los principales defensores de la importancia de la búsqueda de mercados en la expansión colonial ha sido la Escuela de Wisconsin, encabezada por William A. Williams y continuada con las investigaciones de Walter Lafeber y Thomas McCormick. Una opinión contraria a estas teorías se puede encontrar en WELCH, Richard: Response to Imperialism. The United States and the Philippine-American War, 1899-1902, Chapel Hill, The University of North Caroline Press, 1979, cap. 5: «Business, Labor and Self-Interest», págs. 75-88.

34 El 25 de Marzo el Presidente recibió un telegrama de un asesor suyo desde Nueva York en el que se afirmaba que «las grandes coorporaciones de aquí creen ahora que vamos a tener guerra. Creáme que todas van a acogerla como un alivio después de tanto suspense», Papeles de William McKinley, W. C. Reick to J. R. Young, 25 Marzo de 1898, Biblioteca del Congreso, Washington. Lo mismo le hizo saber la National Association of Manufacturers, creada en 1895 e interesada en expandirse sobre nuevos mercados para reactivar la economía y susperar la depresión de 1893. Otros ejemplos serian los del Comnodore Melville, GW: «Our Future in the Pacific. What we have there to hold and win", North American Review, CLXVI, 1898, 281-296; SHAw, Albert: Review of Reviews, XVII, 1898: «The Pacific Ocean is to be the theater of great events in the coming century. The next two generations of Americans will insist upon playing a large part in those events», pág. 143; Irving M Scott, manager de la Union Iron Works; Charles Cramp, lider de la industria naval norteamericana; o el asistente del Tesoro, Frank Vanderlip.

Hixpania, LVII/2, пu่m. 196 (1997) 55I-588 
La documentación norteamericana revela también la disposición del Gobierno a apoyar estos proyectos. Es difícil pensar que un político que había sido miembro del partido republicano durante muchos años, en una época en que esta formación estaba íntimamente unida al mundo de los grandes negocios, ignorara los intereses de estos sectores a la hora de decidir la política internacional a seguir. McKinley había ganado mucha de su importancia politica apoyando altas tarifas que protegían las industrias americanas de la competencia extranjera. Pero si en los últimos años del siglo el mundo económico, consciente de que el mercado interior parecía incapaz de absorber la abundante producción agrícola e industrial, abogó por exportar estos excedentes y le pidió que apoyara la búsqueda de nuevos mercados para incentivar la economía, probablemente, el Presidente tuviera muy en cuenta sus indicaciones. A través de los discursos y declaraciones de McKinley y de los miembros de su Administración podemos comprobar que se mostraron dispuestos a impulsar el comercio exterior. Se refirieron a la necesidad de construir una marina mercante que favoreciera las relaciones comerciales con otros países. Usaron los resortes gubernamentales para apoyar las oportunidades de engrandecimiento económico norteamericano en diferentes partes del mundo. Y al fijar la política arancelaria, defendieron acuerdos de reciprocidad que estimularan las exportaciones americanas ${ }^{35}$.

Según LAFEBER: «The eastern business groups, long afraid of war, now felt that battle was preferable to the fears generated by Proctor's speech and the other events of February and March. New York business leaders had concluded that the United States could safely pay for a war without having to coin silver. Many midwestern and western business groups, as well as nationwide commercial journals who were frightened over the threat to the open door in Asia, had long supported war. The bussiness community was uniting behind McKinley's military preparations», LAFEBER, Walter: The American Age. U.S. Foreign Policy at Home and Abroad. 1750 to the Present, New York, Norton \& Company, 1994, pág. 201.

Por su parte Pratt af irma: «American businessmen, who had generally oppposed intervention in Cuba and had seen no need for colonies, underwent a sudden conversion on the latter point in the spring of 1898. It was at this time that American business was taking alarm at the aggressions of the powers in China. In February and March, chambers of commerce and boards of trade in cities on both the East and the West coasts of the United States were urging the State Department to take energetic measures for the protection of American interests. An American Asiatic Association was formed in New York to agitate for the preservation of American rights and interests in the Orient. The New York Journal of Commerce, which had hitherto scoffed at colonies, istmian canal schemes, and big-navy programs, now declared itself in favor of an isthmian canal, the annexation of Hawaii, and an increased navy, all for the purpose of strengthening the United States in the Pacific and safeguarding its tights in Chinan PRATT, Julius W: A History of Unites States Foreign Policy, New York, Prentice hall Inc, 1955, pág.385.

35 En este sentido McKinley afirmaba: «Incidental to our tenure in the Philippines is the commercial opportunity to which American statesmanship can not be indifferent. It is just to use every legitimate means for the enlargement of American trade; but we seek no adventages in the Orient which are not common to all. Asking only the open door for ourselves, we are ready to accord the open door to others. The commercial opportunity which is naturally and inevitably associated with this new opening depends less on large territorjal possesion that upon an adequate commercial basis and upon

Hispania, LVII/2, nủm. 196 (1997) 551-588 
Finalmente, el tercer elemento que impulsó a los norteamericanos hacia una política exterior expansiva fue de tipo ideológico. La convicción de las excelencias del modelo político y de las instituciones desarrolladas por los Estados Unidos hizo que muchos ciudadanos, que nunca hubieran apoyado el expansionismo por razones económicas o de prestigio, aceptaran que su país tenía un deber que cumplir con las demás naciones y en particular con las menos favorecidas. Los sentimientos de deber, de misión democrática y civilizadora, estaban fuertemente arraigados en aquella época. Estos argumentos morales proporcionaron a Estados Unidos una justificación sobre la que basar la política expansiva que demandaban los círculos que deseaban el engrandecimiento internacional o la adquisición de nuevos mercados ${ }^{36}$.

broad and equal privileges?. 55th Congress, 3d Session, House of Representatives, Instructions to the Peace Commissioners, Washington, 16 September 1898, Papers relating to the Foreign Relations of the United States, 1898, Washington, Government Printing Office, 1901, pág. 907.

Por su parte Frederic Emory, jefe de la Oficina para Comercio Exterior del Departamento de Estado declaraba en 1900: «The territorial expansion of the United States came as incident of the commercial expansion...The recent acquisitions are but outposts of our future trade, and their chief importance consists not in their own resources and capabilities, but in their unquestionable value as gateway for the development of commercial intercourse with the Far East", "Our Growth as a World Powem, The World's Work, I, 1900, pág.65.

En Junio de 1898 el propio Secretario de Estado recomendaba al Secretario del Tesoro potenciar el comercio con China: «The United States, though it has made no acquisition of Chinese territory, is in a position to invite the most favorable concessions to its industries and trade. Inasmuch as our commercial relations with China are already most friendly, and the existing trade between the Unjted States and China is in actual process of development, it would seem to be clear that the present is a golden opportunity for enlarging the channels of commercial intercourse with the Empire...The Chinese Empire has an area about one-half that of the United States, exclusive of Alaska, with a population over 400.000 .000 . Its foreign commerce amounts to about $\$ 200.000 .000$. In 1896 Great Britain had more than two-thirds of China's commerce, Japan ranking second with about one-eleventh, and the United States third with one-twelfth. In other words, The United states has already a large share of Chinese trade than any European country other than Great Britain. China's industrial development is in its infancy, but within the last few years a number of cotton mills have been built and railroads projected, largely with the aid of Ammerican enterprise and industry. The Empire has numerous deposits of coal, iron, copper and other mineral products, affording an unlimited fiels for development. The total trade of the United States with China is....approximate $\$ 35.000 .000 . »$ Commercial Relations of the United States with Foreign Countries during the year 1898. Issued from the Bureau of Foreign Commerce, Department of State, Washington, Government Printing Office, 1899, vol. I, pág. 130.

Las recomendaciones no debieron caer en saco roto, porque en 1898 el asistente del Secretario del Tesoro, Frank Valderlip, observaba a su vez; «Las Filipinas van a ser el Hong-Kong de los Estados Unidos, desde el cual los americanos podrán comerciar con los millones de habitantes de China, Corea, la Indochina francesa, la península Malaya, las islas de Indonesia e indudablemente con Japón e India», Lafeber: Op. cit. pág. 217.

36 Sentimientos que se podian poner en relación tanto con la doctrina del «Destino Manifiesto», nacida en los Estados Unidos en los años cuarenta (MERCK, Frederick: Manifest Destinity and Mission in American History, New York, Knopf, 1963 y HofstadTER:, Richard, The Paranoid Style in American Politics. Cuba, Philippines and Manifest Destinity, New York, Alfred A. Knopf, 1952), 


\section{Los problemas de la política exterior. Crisis en Cuba y en el Extremo Oriente}

McKinley se encontró con varios problemas de política exterior que requirieron una urgente atención en los primeros meses de su Presidencia: una crítica situación en Cuba y un alto interés norteamericano hacia esta isla; el debate sobre el futuro de Hawai; el dilema de la participación en lo que parecía el inminente reparto de China; el conflictivo gobierno tripartito de Samoa; la construcción de un canal interocéanico. Eran cuestiones que estaban íntimamente entrelazadas y que se entendían en el mismo contexto internacional de la expansión imperialista. De las decisiones que McKinley tomara respecto a estos temas dependería no sólo el papel que Estados Unidos desempeñaria en la escena internacional bajo su mandato, sino que sentarían las bases de la política exterior norteamericana en el siglo $\mathrm{xx}$.

Nos vamos a ceñir en este trabajo a dos de las cuestiones enunciadas: la crisis antillana y la crisis en el Extremo Oriente. La insurrección iniciada en Cuba en 1895 estaba dañando seriamente el comercio y las inversiones norteamericanas. A partir de 1897 aumentaron los círculos -prensa, hombres de negocios, militares y estrategas - que señalaron que España estaba perdiendo el control de la situación y que los sectores cubanos más revolucionarios podían hacerse con el gobierno de la isla. Desde la perspectiva americana las circunstancias políticas y económicas parecían tan graves que se fue extendiendo en Estados Unidos un clamor en favor de la intervención en Cuba.

El Gobierno norteamericano inicialmente no quería llegar a una guerra por Cuba. Pero deseaba tener la isla bajo control, tanto por motivos de seguridad nacional y de estrategia en el continente americano, como por el descalabro económico que la insurrección estaba causando a sus intereses. Quería, además, que el fin de la revolución en Cuba y la restauración de la confianza de los medios de negocios fueran triunfos del Partido Republicano, en un

\footnotetext{
como con las teorias del darwinismo social que promulgaba la existencia de naciones más poderosas y desarrolladas, con regímenes políticos avanzados, que debían ejercer su influencia sobre los pueblos más débiles, atrasados o «moribundos» según las palabras del Premier británico, Lord Salisbury, en un discurso que tuvo una extraordinaria repercusión en la sociedad internacional de la época (Discurso del 4 de Mayo de 1898 en el Albert Hali durante la reunión anual de la Primrose League, publicado en The Times, 5 Mayo 1898).

El propio McKinley utilizaba esos mismos argumentos de deber moral al defender la posición de los Estados Unidos en la guerra: «We took up arms only in obedience to the dictates of humanity and in the fullfillment of high public and moral obligations. We had no dessign of aggrandizement and no ambition of conquest... it is believed that in the practical application of these guiding principles the present interests of our country and the proper measure of its duty, its welfare in the future, and the consideration of its exemption from unknown perils, will be found in full accord with the just moral and human purpose which was invoked as our justification in accepting the warn. 55 th Congress, $3 \mathrm{~d}$ Session, House of Representatives, Instructions to the Peace Commissioners, Washington, 16 September 1898, Papers relating to the Foreign Relations of the United States, 1898 , Washington, Government Printing Officé, 1901, págs. 906-908.
}

Hisponia, LVIJ/2, num. 196 (1997) 55I-588 
momento especialmente delicado desde el punto de vista de la política interna, ya que el avance de los demócratas ponf́a en duda el futuro republicano. El convencimiento, después de muchos meses de negociación, de que los españoles no cederían sus derechos de forma pacífica frente a las presiones americanas, y el temor ante el avance de los sectores más revolucionarios de la insurrección cubana, persuadieron a McKinley de la necesidad de intervenir en Cuba si quería obtener el control de la isla.

En este esquema, entró en juego un nuevo factor que iba a ejercer una gran influencia en la conducta del Gobierno americano: las grandes potencias parecían a punto de iniciar la distribución definitiva del Extremo Oriente y los Estados Unidos podían quedar fuera de ese proceso. En los primeros meses de 1898 se agudizó la crisis en Oriente. Japón, tras la victoria en la guerra chinojaponesa de 1895 había ocupado ricos territorios agrícolas y mineros del viejo Imperio. En Noviembre de 1897, Alemania, con la excusa del asesinato de dos de sus misioneros, demandó como indemnizaciónh la ocupación del puerto de Kiaochow, situado en la entrada de la provincia de Manchuria, y que controlaba una ruta muy utilizada por comerciantes norteamericanos que operaban en China. Ante la concesión hecha a Alemania, otras potencias europeas exigieron compensaciones similares, se adueñaron de puertos estratégicos y reclamaron su influencia sobre el área que los rodeaba: Rusia, de Port Arthur en Diciembre de 1898; Gran Bretaña, de la cuenca del Yangtzé en Febrero de 1898 y del puerto de Weihaiwei en Marzo de ese mismo año; Francia, de Kwangchow en Abril de 1898. La integridad de China y la política de puertas abiertas, apoyadas tradicionalmente por Estados Unidos parecían en peligro.

Diplomáticos destacados en la zona ${ }^{37}$, exportadores norteamericanos y periódicos económicos señalaron que la crisis amenazaba el futuro del comercio americano allí donde prometía más interés. Baste recordar que el imperio chino era fundamentalmente agrícola, tenía una población cercana a cuatrocientos millones de habitantes y parecía un mercado especialmente atractivo para los productos manufacturados norteamericanos ${ }^{38}$. También sociedades

37 El diplomático Charles Denby, jefe de la misión de los Estados Unidos en China durante trece años, escribió continuos informes animando a la inversión en este pais, al que veía enormes posibilidades, antes de que su mercado fuera monopolizado por otras naciones. Por cjemplo, Dispatch from Denby to John Sherman, 31 January 1898; Denby to Sherman, 3 April 1898, National Archives of The United States, RG 59, Department of State, Communications from Special Agents, M 37.

38. En la década de 1890 los intereses norteamericanos en China empezaron a consolidarse. Entre 1895 y 1900 las exportaciones a este país se cuadriplicaron, hasta flegar a 15 millones de dólares -otras cifras las elevan hasta los 35 miliones de dólares-. Realmente el mercado chino representaba sólo un $2 \%$ del total de las exportaciones americanas, pero observando cómo habian aurnentado en esos últimos cinco años, las previsiones eran muy optimistas pensando en el potencial que ofrecia un mercado de millones de habitantes. De hecho hubo empresas exportadoras que volcaron sus intereses en el mercado chino, en especial industrias textiles, petroleras, extractoras de mineral de hierro, cobre o acero y productoras de bienes manufacturados que iban desde cuchillos y paraguas a instrumentos cientificos y maquinaria. También empresas importadoras de cáñamo, té, azucar, harina, especias, seda, pieles, porcetanas y maderas. Informes Consulares de 1898, Commercial Relations of the United States with Foreignt Countries during the year 1898 . Issued from the Bureau of Foreign Commerce, Department of State, Washington, Government Printing Office, 1899 , 
misioneras, muy implicadas en la evangelización y educación de estos territorios, solicitaron protección para sus actividades -entre ellas que cabe destacar una importante presencia de mujeres - ${ }^{39}$. Se extendió entonces por los Estados Unidos una corriente en favor de la intervención norteamericana en Oriente.

vol. J. Tambien en: Committee of American Merchants in Shangai to President of the New York Chamber of Commerce, 16 March 1898, National Anchives of The United States, RG 59, Ms 37.

El consul americano en Chefoo, Fowler, comparando el valor del comercio de diferentes paises con China, explicaba en Agosto de 1898: "Comparing these figures with those for 1890, it will be seen that, while Great Britain has not quite doubled, the United States has trebled her exports to China in the last eight years; that Great Britain's purchases have decreased, while those of the United States have more than doubled; that the value of United States exports to China is greater than those of all continental European and the Russians European and Asiatic. The United States bought more of China than either Great Britain, Japan, or al! the Russias...I firmly believe that our trade sales to China last year amounted to nearly $30,000,000$ taels $(\$ 22,170,000) \ldots$ It is also shown that in 1897 the imports of all our goods were four times as large as those for 1893m. Consular Reports, num. 215, August 1898, Commercial Relations of the United States with Foreign Countries during the year 1898. Issued from the Bureau of Foreign Commerce, Department of State, Washington, Government Printing Office, 1899, vol. l, págs. 127-128.

En el informe anual correspondiente a 1898 el mismo consul informaba de la importancia comparativa que tenían las ventas norteamericanas de algodón manufacturado y de aceite de keroseno: «The sales of American cotton manufactures in Chefoo alone in $1897(\$ 1.523 .022,76)$ exceded those to any country or colony in the whole world, were greater in value than our sales in this line to Great Britain and Ireland and all Europe combined and represented one-fourth of the entires sales to China. Of American kerosene oil, Chefoo bought 5.281 .060 gallons, valued at $\$ 547.072,38$, more than to all the Central American States and British Honduras, all the West Indies, and one-sixth of the sales in this line to all Chinar. Señalaba también la necesidad de establecer bancos norteamericanos en China: «One of the greatest needs of the American merchants is an American Bank in China. There is a large field for it, and I feel confident that if one of our New York banking houses established a branch in Shanghai, they would reap a handsome reward. There are in China, French, Russian, German, and several English banks; and it is through these that all United States trade is conducted, involving a great loss to our commerce. I have hopes that ere long, some one will prove enterprising enough to enter this field. There is none more profitable in the world. The Hong-Kong and Shanghai bank's shares sell at 215 per cent premium. There is also a most promising opening for fire-insurance companies»). Consular Reports, 24 October 1898, Commercial Relations of the United States with Foreign Countries during the year 1898. Issued from the Bureau of Foreign Commerce, Department of State, Washington, Government Printing Office, 1899, vol. 1, págs. 128-129.

Entre los historiadores norteamericanos que han trabajado sobre cuestión destacan los trabajos de Thomas McCormick. Su tesis fundamental defiende la importancia del mercado chino en la expansión norteamericana: «Hawaii, Wake, Guam and the Philippines were not taken principally for their own economic worth, or for their fullfillment of the Manifest Destinity credo... They were obtained, instead, largely in an eclectic effort to construct a system of coaling, cable and naval stations into an integrated trade route which could facilitate realization of America's one overriding ambition in the Pacific - the penetration and, ultimately, the domination of the fabled China market», en «insular Imperialism and the Open Door: The China Market and the Spanish American War», Pacific Historical Review XXXIJ, Mayo 1963, 155-69, pág. 155.

39 «Ningún grupo estuvo tan implicado y tan interesado en China como los misioneros cristianos. Salvar almas era un objetivo incluso superior al beneficio económico de su mercado. Entre 1870 y 1900 las misiones en China aumentaron un $500 \%$. Sólo en la década de los noventa los

Hispanit, LVII/2, nủın. 196 (1997) 551-588 
En esa coyuntura, se planteó la posibilidad de encontrar una solución conjunta a los problemas planteados en el Caribe y en el Extremo Oriente. Si se declaraba una guerra con España, y los Estados Unidos intervenían a un tiempo en sus colonias occidentales y orientales, acabarían con la insurrección en Cuba y alguna de las islas españolas en el Pacífico podría convertirse en una base militar desde la que proteger los intereses norteamericanos en Asia. De esta forma resolverían la crisis cubana y la crisis oriental a un tiempo ${ }^{40}$.

McKinley empezó a desplegar cautelosamente la política que quería desarrollar. Después de la destrucción del Maine se movilizó rápidamente para preparar la nación para la guerra. El 9 de Marzo consiguió que el Congreso autorizara emplear cincuenta millones de dólares para reforzar la Marina y el Ejército. Entre el 20 y el 28 de Marzo envió una serie de peticiones al Gobierno español, cada vez más difíciles de cumplir, a pesar de la buena voluntad que mostró el Gobierno de Sagasta. Solicitó, por último, que España negociara con Estados Unidos la independencia de Cuba. Ningún grupo político en Madrid estuvo dispuesto a pagar el precio que supondría aceptar tales concesiones. El 11 de Abril, McKinley envió un mensaje al Congreso en el que solicitaba permiso para comenzar una guerra que acabara con la lucha que en los últimos tres años había destruido las vidas y las propiedades de los americanos en Cuba.

\section{PLANTEAMIENTO ORIENTAL DE LA GUERRA HISPANO-NORTEAMERICANA}

En la expansión de los Estados Unidos por el Pacífico durante la guerra con España hay tres cuestiones que han sido muy debatidas y sobre las que existen interpretaciones muy diferentes. En torno a ellas se centra la controversia sobre si existió un cálculo deliberado en la actuación norteamericana en el Extremo Oriente. La intencionalidad respecto a este proceder se cuestionaría en el ataque de Dewey a Manila, en la consolidación de la victoria y en la anexión final de todas las Filipinas.

misioneros norteamericanos doblaron su número hasta sobrepasar el millar. Estos misioneros desatrollaron su labor religiosa, al tiempo que representaron patrioticamente a su nación e impulsaron los intereses económicos. Salvaban las almas, vestían los cuerpos con textiles de Carolina del Norte e invertian en tierras y minerales chinos. Por ello solicitaron la protección del Gobierno americano en China». LAFeber, Walter, The American Age. U. S. Foreign Policy at Home and Abroad. 1750 to the Present, New York, Norton \& Company, 1994, págs. 2218-219.

Es de resaltar la participación de las mujeres en este movimiento. En I880 sólo existían 20 sociedades de mujeres misioneras. En 1915 tres millones de mujeres apoyaban cuarenta sociedades. Estaban convencidas de la importancia de su fabor como misioneras y educadoras en el Extremo Oriente; empeñadas en mejorar la sanidad, construir hospitales, enseñar a leer, defender los derechos de la infancia y de la mujer en campos como la salud, la educación, la vida familiar y laboral, en unas naciones que consideraban muy atrasadas respecto al resto de países civilizados.

40 Walter LaFeber lo resumía muy gráficamente con una frase: «Two crises, one wan: The American Age. U.S. Foreign Policy at Home and Abroad. 1750 to the Present, New York, Norton \& Company, 1994, pág. 197. 
Partimos de una hipótesis previa. La guerra hispano-norteamericana tuvo una dimensión oriental porque los Estados Unidos atacaron Filipinas e implicaron a los archipiélagos españoles del Pacífico en un conflicto que en principio no guardaba ninguna relación con ellos. Fue una iniciativa estrictamente norteamericana, para proteger las costas orientales de los Estados Unidos de un eventual ataque español, en caso de enfrentamiento armado entre los dos países. Sin embargo, a pesar de lo que se dijo en medios políticos, entre oficiales de la Marina e incluso en la prensa estadounidense, España nunca hubiera llevado la guerra a aquél ámbito, ni desde aquellas islas se hubiera podido amenazar territorios americanos. En primer lugar, esta posibilidad no estuvo en el ánimo de los gobernantes ni de los estrategas españoles. Y segundo, carecían totalmente de medios con que efectuar tal acción. Sus efectivos en el Pacífico difícilmente cubrían la defensa ni las comunicaciones de sus propias islas. Cualquier estudioso de la presencia española en Oriente, consciente de la fragilidad de la flota, de las carencias en sus comunicaciones, de la dificultad para asegurar los correos períodicos que unían Filipinas con las islas Micronesia, de los problemas que se creaban en aquellos archipiélagos cada vez que surgía una eventualidad, un levantamiento o un conflicto que requería la presencia de barcos en un territorio alejado de los puntos ocupados, no podrá por menos que dudar sobre las posibilidades de una acción española contra las costas americanas del Pacífico.

No obstante, la afirmación relativa a que la decisión de implicar a los territorios orientales en la guerra partió de los norteamericanos, no cuestiona que el conflicto entre España y Estados Unidos se planteó por Cuba y que sin los problemas del Caribe el Gobierno de McKinley no hubiera programado una intervención contra las islas españolas del Pacífico. En este punto coincidimos totalmente con las interpretaciones que se han hecho en tal sentido. Pese a ello, la documentación manejada permite aseverar que en el momento de declarar la guerra a España, los intereses orientales tuvieron una importancia nada desdeñable ${ }^{41}$.

41 La posibilidad de una intervención norteamericana en Filipinas, se había planteado desde fechas inuy tempranas. Justo en el momento en que Henry lde, representante de la justicia norteamericana en Samoa, urgía a su Gobierno a consolidar las ventajas ya adquiridas tanto en aquellas islas como en Hawai, señalando que las demás potencias estaban completando el proceso de anexión de las islas de! Pacifico, pareció que se abrian nuevas posibilidades en ese Océano. La rebelión iniciada por los fílipinos en 1896 despertó una viva especulación internacional sobre quien se quedaría con las Filipinas si los españoles se mostraban incapaces de retenerlas. Japón, Gran Bretarta, Alemania y Francia aparecian como los herederos más probables. El interés por esta cuestión se extendió entre la opinión pública americana a través de las columnas de distintos períodicos, que llegaron a calificar a las Filipinas como la Cuba del Extremo Oriente, resaltando las oportunidades que ofrecía como puerta del comercio con el Exıremo Oriente y señalando las oportunidades que en tal sentido abriría para los americanos una guerra contra España. Literary Digest, XIV, 1896, 22, 342, 407, 681, 743; XV, 1897, 759; BARRET, John: «The Cuba of the Far East» in North Anerican Review, CLXIV, 1897, 173-180.

Hispanisi, LVII/2, เu่m. 196 (1997) $551-588$ 


\section{El ataque de Dewey a Filipinas}

En tal sentido, es significativo que al comenzar las hostilidades, el primer movimiento norteamericano fuera un ataque a Filipinas. Cabe preguntarse si dicha acción fue un objetivo bélico previamente decidido y si implicaba intenciones ulteriores. Este ha sido un problema histórico muy debatido, que continúa abierto a distintas interpretaciones. Parece probado que la acción de Dewey se basó en planes navales previos, que respondian a razones de estrategia bélica. Se trataba de acabar con la flota española en Oriente para evitar cualquier ataque a las costas orientales de los Estados Unidos que pudiera obligarles a abrir un segundo frente en el Pacífico. Fue, pues, en origen una acción puramente preventiva, que no conllevaba ningún otro objetivo por parte de los estrategas que la concibieron ${ }^{42}$.

A partir de 1896, la Marina norteamericana comenzó a elaborar una serie de estudios en los que se analizaban posibles líneas de actuación para el caso de que se planteara un conflicto con España. Las formulaciones de esa política se iniciaron con un informe elaborado por un oficial de la Oficina de Inteligencia de la Marina, el teniente de navío William Wirt Kimball, en el que se recomendaba un ataque al flanco español más débil, Filipinas ${ }^{43}$. En los años sucesivos distintos oficiales de Marina continuaron desarrollando planes relativos al Extremo Oriente ${ }^{44}$, y en Septiembre de 1897 Theodore Roosevelt presentó a la aprobación presidencial un memorándum en el que se establecía que si estallaba un conflicto hispano-norteamericano, inmediatamente un escuadrón asiático bloqueara y tomara Manila ${ }^{45}$. Esos planes fueron conocidos y aceptados por McKinley y por su Gobierno, que eran plenamente conscientes de la dirección en la que se estaba trabajando.

42 Young, George B. \& Grenville, John A. S.: Politics, Strategy and American Diplomacy: Studies in Foreign Policy, 1873-1917, New Haven, Yale University Press, 1966. GRENviLLE, John A. S.: «American Naval Preparations for War with Spain, 1896-1898», Journal of American Studies, 2, J, 1968, 33-47.

${ }_{43}$ Memorandum, 1 June 1896, Record Group 38, General Records of the Office of Naval Intelligence, National Archives of the United States. Se indicaba también que con ello se privaria, además, a España de una base naval donde reponerse y se obtendria una baza con la que negociar una indemnización cuando la guerra acabara. En «War with Spain, 1896. General Considerations of the War, the results desired and the consequent kind of operations to be undertaken. Plan by W W Kimball, L T, U. S. Navy, Staff Inttelligence Officer, I June 1898, RG 313, Naval Operating Forces, North Atlantic Station, Entry 43, Box 11, Navy Department, National Archives of the United States.

44 Planes efectuados por los of iciales TAYLOR, WAINWRIGHT y MCADOo. «Memorandum regarding Naval Attachés Abroadn, 15 April 1897, R G 80, Entry 124, Records of the Asistant Secretary of the Navy, National Archives of the United States.

45 Theodore Roosevelt to Henry Cabot Lodge, 21 September 1897, Roosevelt MSS, cit. por McCormick, $O p$. cit., pág. 74. La linea propuesta en este memorandum no sólo estaba inspirada por Roosevelt, sino que el desarrollo de los planes de guerra fuc responsabilidad de la Office of the Naval War Board, al frente de la cual estaba el capitán Crowninshield. 
En esta cuestión se ha querido otorgar a Roosevelt mayor importancia de la que realmente tuvo, haciendo recaer sobre una acción suya la responsabilidad del ataque de Dewey a Manila, cuando en realidad el comandante del escuadrón oriental tuvo para ello el respaldo completo del Presidente, que fue, además, quien dio la orden definitiva de marchar sobre Filipinas. El origen de esta interpretación nació de una iniciativa tomada por Theodore Roosevelt el 25 de Febrero de 1898. En esa fecha, el joven ayudante del Secretario de Marina, convencido defensor de la necesidad del engrandecimiento exterior de los Estados Unidos y partidario de una política expansiva, aprovechó una ausencia de su superior para, basándose en los planes previamente diseñados, enviar una serie de cables a todos los oficiales al frente de escuadrones de barcos, con el objeto de que se prepararan para una acción inminente contra España. Al conocer McKinley esa iniciativa, revocó las órdenes enviadas. Y las revocó en todos los escenarios, excepto en el Pacífico, lo cual reafirma la tesis de que indudablemente respaldaba la política prevista para Filipinas ${ }^{46}$. Consecuentemente con las instrucciones recibidas, Dewey intensificó los preparativos del Escuadron asiático; aceptó entablar contactos con los insurrectos filipinos para que colaboraran en la intervención norteamericana en aquellos archipiélagos; finalmente, nada más conocer la declaración de guerra, y después de recibir un nuevo telegrama de Long - aprobado por el Presidente ${ }^{47}$. atacó Manila y aniquiló la escuadra de Montojo. Cumplidos con esta acción los objetivos previstos, la historia pudo acabar aquí ${ }^{48}$.

46 Theodore Roosevelt to George Dewey, 25 Febrero 1898, Ciphers sent., 1888 1898, Record Group 45, National Archives of the United States, Washington DC.

47 «War has commenced between the United States and Spain. Proceed at once to Philippine Islands. Commence operations particularly against Spanish fleet. You must capture vessels or destroy. Use utmost endeavor" Autobiography of George Dewey, London Constable \& Co., 1913, pág. 195. En una carta personal que el Secretario de Marina escribió a Agnes Lodge, el 9 de Octubre de 1898, Lodge explicaba cómo la decisión final para atacar Manila se tomó en una reunión que tuvo lugar en la Casa Blanca el domingo 24 de Abril de 1898. Siguiendo los planes previstos, fue el propio Presidente quien firmó la orden que le llegó a Dewey: «The war was declared Thursday Apri\} 21st. I immediately went to the President and told him that it was the judgment of the Department and the leading officers there that he should order Dewey immediately to Manila to attack the Spanish forces. He prefered to considered the matter a little longer. On the following Sunday morning l went over again and took with me the despatch, as it was afterwards signed and sent...The Ptesident ordered it sent, and it went that afternoon"y.

48 «While remained at war with Spain our purpose must be to strike at the power of Spain wherever possible. The question of making the Philippine Islands United States territory was one policy for the nation at home to decide, which had nothing to do with my duties as a naval officer... On May 13 , in my report of conditions l once more emphasized the fact that I could take the city at any moment; and now 1 impressed upon the goverment at home the necessity, if it were our intention to occupy Manila, that a force of occupation should immediately be sent»... «The effect of the victory had precipitated a new element in the mastery of the Pacific and in the international rivalty for trade advantage in the populous Orient. Hitherto the United States has been considered a second-class power, whose foreign policy was an unimportant factor beyond the three-mile limit of the American hemisphere. By a morning's battle we had secured a base in the Far East at a juncture in international relations when the parceling out of China among the European powers seemed imminent) Autobiography of George Dewey, London Constable \& Co., 1913, págs. 239-240 y 250.

Hi.pania, LVII/2, núm. 196 (1997) 551-588 
Las discrepancias de los historiadores respecto a estos incidentes comienzan al plantearse si el Gobierno de McKinley, previamente a la victoria de Cavite, tuvo el propósito de aprovechar la acción de Dewey para conseguir una base naval en Filipinas; si planeó desde un principio la toma de todo el archipiélago; o si, por el contrario, nunca pretendió ninguno de estos objetivos y se limitó a actuar en el Oriente en respuesta a los sucesos ocurridos Manila, que abrieron horizontes inesperados a la expansión norteamericana.

Una interpretación muy extendida sostiene que fue la victoria de Dewey la que por vez primera planteó la posibilidad de adquirir una base naval en Filipinas y que sólo posteriormente surgió la necesidad de quedarse con todo el archipiélago. Según esta versión fueron las dudas sobre cúal sería la actuación más conveniente a seguir en aquellas islas, las que determinaron el envío de tropas con que consolidar en tierra la victoria de Dewey en Cavite, mediante la conquista de Manila. El objetivo era conseguir que, caso de decidir que para los Estados Unidos sería provechoso hacerse con parte o con la totalidad de las Filipinas, ello fuera posible y pudiera basarse en el derecho sobre territorios conquistados. El Gobierno de McKinley debatió de Junio a Octubre la línea de conducta a seguir, hasta que finalmente se decidió por la anexión de las Filipinas a fines de ese último mes ${ }^{49}$.

Esta interpretación de los hechos implicaría a un Presidente McKinley que no relacionó en ningún momento el ataque de Dewey a la flota espa. ñola con la posible obtención de una plaza desde la que defender sus intereses en Oriente; poco consciente del alcance de las decisiones que tomaba; inacapaz de imaginar que si las tropas norteamericanas conquistaban Manila se vería en una tesitura similar a la que se encontró, ni de pensar que si se adueñaban de Manila tendrían que decidir qué querían hacer con el resto de Filipinas; un Presidente que no calculó que estos hechos provocarían una respuesta tanto en las islas como en la comunidad internacional. La versión reforzaría la imagen de McKinley como un político con unas ideas muy poco claras en asuntos exteriores, ajeno a posibles intereses en el Pacífico, indeciso sobre la conducta a seguir y forzado por los acontecimientos a adoptar una política en Filipinas que no deseó ni planificó previamente.

Una segunda tesis se inclinarfa por la existencia de premeditación política en el ataque a Filipinas. Si bien la acción de Dewey continuaría respondiendo a los planes tácticos anteriormente citados, paralelamente, tras estos planes podría encontrarse a un Presidente McKinley consciente de las implicaciones que tal acción provocaría y deseoso de hacerse con una base naval en Filipinas para desde ella afianzar los intereses políticos y económicos de Estados Unidos en el Extremo Oriente, en Hawai y en el Pacífico. Existiría, por tanto,

49 WELCH, R E.: Response to Imperialism. The United States and the Philippine-American War; J899-1902, Chapel Hill, The University of North Caroline Press, 1979. 
un cálculo en su actuación, aunque ello no implicaría la pretensión inicial de hacerse con todo el archipiélago filipino ${ }^{50}$.

Ante estas dos opciones, y a la luz de la documentación que hemos podido consultar, nos inclinamos por un Presidente que actuó sabiendo qué podía pasar y qué estaba haciendo. McKinley era un político prudente, bien informado y con buenas conexiones con los círculos económicos, militares y políticos de su país. Si bien no hay papeles que permitan afirmar que deseara tomar las Filipinas y sus palabras desmienten ambición territorial alguna ${ }^{51}$, su actuación a lo largo de la guerra parece sugerir que apoyaba la opción de hacerse con una base naval, provisional o permanenternente. Sólo asi se conciliaría un respaldo a la acción de Dewey consciente de las implicaciones que conllevaba y su rápida acción tras la victoria. Sin embargo, el problema de la anexión del resto de las islas sería una cuestión planteada a posteriori, ante el curso de los acontecimientos.

\section{La consolidación de la victoria: los instrumentos para la expansión}

Al conocer la victoria de Cavite, ¿cúál fue la reacción del Gobierno de McKinley? Emprender una serie de acciones encaminadas a afianzar rápidamente la posición norteamericana en Filipinas. Acciones francamente difíciles de llevar a cabo a no ser que estuvieran preparadas de antemano.

El cuatro de Mayo cinco mil hombres, concentrados previamente en San Francisco, fueron enviados a Filipinas con el objeto de consolidar en tierra lo ya conseguido en el mar ${ }^{52}$. El once de Mayo, aún en plena guerra, sin que

so «McKinlcy suavizó las críticas a su política en Filipinas asegurando que había sido empujado involuntariamente hacia la conquista de 'esas condenadas islas' que ni siquiera sabia localizar en el mapa. Su sentido político era bueno, pero la historia era mala. El Presidente sabja muy bien antes de ir a la guerra con Espana lo mucho que podian significar las Filipinas como base desde la que preservar la politica de puertas abiertas en China. La crisis causada por las acciones de Alemania y Japón en territorio chino no le dejaron alternativa, a no ser que quisiera renunciar a todo el trabajo norteamericano de la última centuria para conquistar los mercados asiáticos. $Y$ el Presidente no tenia ninguna intención de hacer algo semejantem. LAFEBER, Walter: Op, cif, pág. 201.

${ }_{51}$ «lt is none the less true, however, that, without any original thought of complete or even partial acquisition, the presence and success of our arms at Manila imposes upon us obligations which we can not disregard. The march of events rules and overrules human action. Avowing unreservedly the purpose which has animated all our effort, and still solicitous to adhere to it, we can not unmindful that, without any desire or design on our part, the war has brought us new duties and responsabilities which we must meet and discharge as becomes a great nation on whose growth and career from the beginning the Ruler of Nations has plainly written the high command and pledge of civilization», 55th Congress, 3d Session, House of Representatives, Instructions to the Peace Commissioners, Washington, 16 September [898, Papers relating to the Foreign Relations of the United States, 1898, Washington, Government Printing Office, 1901, pág. 907.

52 McKinley to Secretary of War, 4 May 1898, Correspondence Relating to the War with Spain, 1902, vol. 2, pág.635, 676-678. El objeto del envío de estas tropas fuc, en palabras de McKinley, asegurar el orden y la seguridad en las islas mientras éstas estuvieran en poder de los Estados Unidos.

Hispasia, LVII/2, nủm. 196 (1997) 551-588 
hubiera habido ningún enfrentamiento definitivo en Cuba y sin que se hubieran planteado siquiera las condiciones para la paz, McKinley aprobó un memorándum en el que solicitaba formalmente a España la cesión de una estación de carboneo en Filipinas, presumiblemente Manila; lo cual implica que desde primeros de Mayo el Gobierno norteamericano estaba intentando asegurarse la posesión de una base naval en el archipiélago oriental ${ }^{53}$. Además, se rompieron las relaciones con Aguinaldo y con los insurrectos filipinos, con el objeto de estar libres de compromisos en el momento de decidir que hacer con estos archipiélagos ${ }^{\mathrm{s}}$.

Al tiempo, se adquirió un rosario de islas y de bases navales a lo largo del Pacífico, que permitieron un enlace perfectamente engarzado a través de posesiones ya americanas, garantizando así las comunicaciones entre San Francisco y Manila. El primer paso fue la conquista de Guam, que ofrecía un especial interés estratégico en la ruta hacia Oriente. El 3 de Junio, el Presidente autorizó que uno de los barcos que se dirigía a reforzar las fuerzas norteamericanas en Filipinas, tomara una isla del archipiélago de las Marianas ${ }^{55}$. En respuesta a estas instrucciones, el 20 de Junio, una escuadra integrada por el crucero Charleston y los transportes Australia, City of Pekin y City of Sideney entró en el puerto de San Luis de Aprà. Las autoridades españolas destinadas en la isla ignoraban el estado de guerra entre su país y los Estados Unidos, y acogieron a los recien llegados con cordialidad y sin recelo. Aprovechando el factor sorpresa, los oficiales norteamericanos hicieron prisioneros a los españoles e izaron la bandera americana sobre Guam. Meses más tarde la isla se convirtió en territorio norteamericano y dada su estratégica posición fue una base fundamental para Estados Unidos en las dos guerras mundiales. A continuación, se libró la batalla final para la anexión de Hawai. Se presentó como una necesidad de guerra. Era vital para la seguridad norteamericana tener esos archipiélagos bajo su control. Conociendo las reticencias de importantes sectores del Congreso, McKinley apeló a una resolución conjunta de ambas Cámaras. A fines de Junio consiguió la aprobación del Congreso, el 7 de Julio el Presidente ratificó la anexión y el 12 de Agosto Hawai se convirtió en territorio de los Estados Unidos ${ }^{56}$. Tiempo después se ocupó Wake, que sería formalmente anexionada en Enero de 1899. Recorde-

Consul francés en San Francisco a M. ${ }^{\circ}$ de Asuntos Exteriores, meses de mayo, junio y julio: correspondencia continuada sobre los movimientos de tropas americanas a Filipinas. En el informe del 20 de Julio incluye una relación detallada de los barcos que han partido, qué oficial les mandaba y cúantos hombres componian cada expedición, Archive Diplomatique du Ministère des Affaires Étrangères, Paris, Correspondence Politique et Commerciale, Espagne, NS 34.

$\$ 3$ State Department Memorandum, 9 May 1898, John B. Moore Papers, Library of Congress, Washington.

${ }_{54}$ General Merritt to Adjuntant General, I August 1898, Correspondence Relating to the War with Spain, 1902, vol. 2, pág. 743 .

ss Diplomatic Instructions, Day to Hay, 3 June 1898, RG 59, M 77, National Archives of the United States.

56. La anexión de Hawai era una de las cuestiones reiteradamente apoyada por los gobiernos republicanos y rechazada por los demócratas. De ahí que una vez que Cleveland dejara la presidencia, 
mos también que los Estados Unidos tenían ya posiciones definidas en Samoà, en Midway, en las Aleutianas y otras pequeñas islas del Pacífico Johnston, Palmyra, Kingman Reef, Howland, Baker- ${ }^{57}$.

McKinley decidiera reabrir la cuestión. Designó una comisión al frente de la cual nombró a John Foster, para evitar así la intervención de Sherman, declarado enemigo de la anexión, hasta el punto que éste ignoró la marcha de las negociaciones, y, poco antes de que el tratado fuera firmado, negó tajantemente al ministro japonés que Estados Unidos estuviera haciendo ningún movimiento en favor de la anexión.

Los partidarios de la anexión de Hawai señalaron que ésta significaría incorporar la economía de las islas al sistema norteamericano. Pearl Harbor se podria convertir en una base naval desde la que proteger la costa oeste de los Estados Unidos. Podría ser también un punto estratégico para el comercio y las comunicaciones con el Extremo Oriente. $\mathrm{Y}$ además permitiría que un pueblo menos desarrollado se beneficiara de las ventajas de las instituciones y de la civilización americana. Por otra parte, en diferentes momentos se señaló que si Estados Unidos no ocupaba las islas, otras naciones, y en especial Gran Bretafia o Japón, podrian intentar anexionarselas, con los consiguientes perjuicios a los intereses norteamericanos.

Naturalmente no todos los sectores veian tan claras las ventajas de la anexión. Los azucareros -los productores, que no los refinadores de azucar-se opusieron a la incorporación a la Unión de unas islas que cultivaban caña de azucar que podría competir con su propia producción. Otros círculos temieron los problemas racíales que podría conllevar la anexión. Las islas tenian no sólo población hawaiana nativa, sino un número muy alto de chinos y japoneses que trabajaban en ellas. Además, se decía que desde un punto de vista estratégico estas islas del Pacífico no serían tan útiles, ya que también eran vulnerables a ataques, y por tanto requeririan un mayor desarrollo de la marina y la adjudicación de tropas y barcos destinados a su defensa. Los sectores antiexpansionistas se opusieron a la intervención en Hawai por creer que iba en contra de los principios politicos y morales que definía la Constitución de los Estados Unidos.

Sin embargo, la cuestión de Hawai, planteada ya en los primeros meses de la presidencia de McKinley, quedó pendiente de resolución hasta que la guerra hispano-norteamericana en curso pareció exigir la inmediata anexión de las islas como parte de la estrategia bélica. Al comenzar las hostilidades con España, McKinley maniobró rápidamente para que el Congreso aceptara la anexión de Hawai. Ya lo habia intentado con anterioridad en Junio de 1897 y la Cámara de Representantes habia rechazado su propuesta. Conocía también la resistencia de los círculos antiexpansionistas y de los azucareros americanos, temerosos de las importaciones de este producto desde Hawai. Sin embargo, en 1898 recurrió a las amenazas japonesas de intervenir en las islas y recalcó lo importante que era para la seguridad nortemaricana tener estos archipiélagos bajo su control. Pero la baza fundamental la encontró en la propia guerra hispano-norteamericana. La flota necesitaba con urgencia una base naval en mitad del Pacífico desde la que acudir en auxilio de las fuerzas que peleaban en Filipinas. Dos dias después de que se confirmase oficialmente la victoria de Dewey en Manila, McKinley volvió a solicitar al Congreso la anexión de Hawai. Como no contaba con los 60 votos necesarios, decidió apelar a una resolución conjunta de ambas cámaras que facilitaría la aprobación, al ser más fácil conseguir de esta forma una mayoria simple. A fines de Junio consiguió pasar la votación y en Agosto Hawai se convirtió en territorio de los Estados Unidos. McKinley declaraba al respecto: «Necesitamos Hawai tanto como en su dia necesitamos California. Es el Destino Manifiesto».

57 Ryden, G H.: The Foreign Policy of the United States in Relation to Samoa, New Haven, Yale University Press, 1933. Dulles, Foster R.: America in the Pacific. A Century of Expansion, Boston, Houghton Mifflin Company, The Riverside Press Cambridge, 1938. GriswoLD, A. Whitney: The Far Eastern Policy of the United States, New Haven, Yale University Press, 1938. GRAEBNER, N A.: Empire on the Pacific, New York, Heath, 1955. BraISTED, William R.: The United States Navy in the Pacific, 1897-1909, Austin, University of Texas Press, 1958. IRIYE, Akira: Across the Pacific. An Inter History of American-East Asian Relations, New York, Harcourt, Brace \& World, Inc., 1967. HEFFER,. Jean: Les Etats-Unis et le Pacifique. Histoire d'une frontiere, Paris, Editions Albin Michel, 1995.

Hispania, LVI1/2, nùm. 196 (1997) 551-588 
Mientras iba afirmando de forma efectiva la posición de los Estados Unidos en el Paćfico, McKinley discutió el futuro de las Filipinas con diferentes círculos de la sociedad norteamericana. En primer lugar, con su propio Gabinete, en el que las opiniones respecto a cúal sería la conducta más conveniente en aquellos archipiélagos estaban divididas. Varios miembros del Gobierno no veían clara la actuación a seguir ya que temían los problemas que podría plantear una presencia permanente en las Filipinas, por lo que algunos apoyaron incluso el abandono de cualquier proyecto relacionado con aquellas islas. Las reuniones del Gabinete se sucedieron a lo largo del verano de 1898, hasta que en Octubre el Gobierno llegó al acuerdo de anexionarse todas las islas ${ }^{58}$. El Presidente consultó también el asunto con expertos estrategas, diplomáticos y hombres de negocios que conocían bien las Filipinas ${ }^{59}$. Recabó la opinión de los miembros de la Comisión de Paz de París ${ }^{60}$. Final-

58 «The instruction sent today about the Philippines has the cordial concurrence of the seven members of cabinet now in Washington, Long being absent in Massachusetts. Gage has written you in the same sense. Let me add your course has the warm approval of us all» Telegram. Personal, Mr. Hay to Mr. Day, Washington, 28 October 1898. 55th Congress, 3d Session, House of Representatives, Papers relating to the Foreign Relations of the United States, 1898, Washington, Govermment Printing Office, 1901.

$\$ 9$ Correspondencia mantenida con el almirante Dewey, los Generales Merritt, Otis y Greene, el Sargento Bourns, el Mayor Dell, el Coronel Jewett, el Cónsul belga en Manila y John Foreman, un comerciante asentado en Manila en 1880. La recomendación mayoritaria de estos hombres fue la adquisición norteamericana de las Filipinas. A modo de ejemplo sobre el espíritu detrás de sus recomendaciones valgan las siguientes frases: «Bourns, several years in the Philippine Islands, considers natives incapables of self-government because of lack of good examples, lack of union between Luzon and throughout archipielago, and existence of race, tribal and religious differences..." (Consul André... says United States must take all or nothing. If southern islands remained with Spain they would be in constant revolt and United States would have a second Cuba... United States should have pity of them (the natives) and show them something better. Under United States islands would increase in wealth and soon return any money laid out. Even Spanish merchands desire American protection. Natives do not desire independence. Present rebellion represents only half of 1 per centum of inhabitants.... «General Merritt thinks that United States attempted to take possession of Luzon or all the group as a colony... Said United States under moral obligation to stay there.... It would simplify if United States took the whole group... He consideres capture Manila practically capture of group... Revenue of whole group would be more than adequate for goverment... It would be better for the other islands and Luzon to be in the possession of a highly civilized power than to remain in the present condition...", 55th Congress, 3d Session, House of Representatives, Papers relating to the Foreign Relations of the United States, 1898, Washington, Government Printing Office, 1901.

60 Especialmente interesante es el documento enviado por los comisionados al Presidente McKinley el 25 de Octubre, en el cual cada uno de ellos expresaba su opinión respecto a la conveniencia de anexionarse las Filipinas. Davis, Frye y Reid manifestaron su creencia de que tas islas no podían ser divididas y que Estados Unidos debia hacerse cargo de la administración de todo el archipièlago: «Great danger must result from division... Commercially, division of archipelago would not only needlessly establish dangerous rivals at our door, but would impair value of part we kept... Moral obligations not to return Manila and Luzon to the oppresive power from which we have relieved them, applies also to the rest of the archipelago... We believe public opinion in Europe, including that of Rome, expects us to retain whole of Philippines and would prefer that to any other solution..." 
mente, calibró el sentir de los ciudadanos de su propio país en un viaje intencionadamente multitudinario que realizó por el medio Oeste a comienzos del Otoño de 1898. Durante su visita, y en contraste con su habitual tono comedido y prudente, McKinley pronunció ardientes discursos en favor de la expansión por Oriente, subrayando las oportunidades históricas que se abrían para la nación en aquél ámbito. Sus mensajes obtuvieron una entusiasta acogida entre la opinión pública, que le brindó el respaldo que buscaba. Era lo que le faltaba para acabar de decidir su política en las Filipinas ${ }^{61}$.

La documentación de los archivos de exteriores de distintos países muestran que, al iiempo, y desde fechas muy tempranas - Mayo y Junio de 1898-. el Gobierno también realizó discretas pero firmes gestiones cerca de las grandes potencias para conocer su posición ante una presencia americana Filipinas, sin revelar ninguna decisión definitiva, pero dejando sentado que no toleraría injerencias en una cuestión que consideraba de incumbencia norteamericana.

Esta secuencia de hechos demuestra que, en los meses inmediatamente posteriores a la victoria de Dewey, el Gobierno de McKinley consolidó la posi* ción americana en el Pacífico y creó los mecanismos necesarios para que en el caso de decidir que era conveniente retenex una parte de Filipinas, esto fuera posible. Entonces fue el momento de decidir cúales iban a ser los límites de la acción norteamericana en estos archipiélagos.

\section{La anexión de las Filipinas: los intereses americanos en el Pacífico}

Conseguidos los resultados tácticos inicialmente propuestos en la guerra y con una base naval desde la que operar en el Extremo Oriente cabían cuatro posibilidades: - retener Manila como base naval, pero sin implicarse en el resto del archipiélago; - retirarse de Filipinas y devolver las islas a España al

Wílliam Day señaló que cra partidario de retener sólo una base naval: «l am unable to agree that we should peremptorily demand the entire Philippine group...» Cuestionaba la conveniencia de iniciar una carrera colonial y resalkaba que obteniendo Luzón conseguirían las ventajas navales, estratégicas y comerciales deseadas, evitando los probiemas con las demás potencias gracias a la concesión de una total libertad de comercio en el archipiélago: «This gives us practical control of the situation, with a base for the navy and comnercial in the East, and responsability for the people to whom we owe obligation...) Finalmente, Gray fue el único miembro de la comisión que no apoyó la adquisición de parte alguna de las Filipinas: «The undersigned can not agree that it is wise to take Philippines in whole or in part...Attacked Manila was part of legitimate war against Spain...Duty would require us to abandon Manila... No place for colonjal administration or goverment of subject people in American system». 55th Congress, 3d Session, House of Representatives, Correspondence with the United States Peace Commissioners at Paris, 1898, Papers relating to the Foreign Relations of the Unted States, 1898, Washington, Government Printing Office, 1901.

(it Los temas principales de estos discursos eran el honor, el deber y la responsabiłidad: «Nuestros hijos están en Filipinas porque por designio de Dios aquel gran archipiélago ha caído en manos del pueblo americano... Pondremos los hombres suficientes detrás de nuestra bandera para mantener nuestra autoridad en Luzón y responder de nuestras responsabilidades» decía McKinley.

Hisponia. LVIt/2, núı. 196 (1997) 551-588 
firmar la paz; - apoyar el autogobierno y la independencia de los filipinos; permitir un reparto entre las potencias o la adquisición total de las islas por parte de otra nación. Ninguna de estas opciones le pareció admisible al Gobierno americano, porque todas ellas perjudicaban sus intereses en la zona. Los expertos habían señalado que retener únicamente Manila no parecía recomendable por cuestiones estratégicas y defensivas. Respaldar el mantenimiento la soberanía española en las islas sería una acción absolutamente impopular en los Estados Unidos, que habían apoyado la guerra en gran medida para liberar a estos pueblos del dominio de los españoles. Por otra parte, ni el Presidente ni sus consejeros consideraron al pueblo filipino lo suficientemente maduro para ejercer un autogobierno. Dejar las Filipinas en manos de otra potencia o grupo de potencias era una opción inaceptable a nivel político, económico y estratégico.

$¿$ Qué factores influyeron en la decisión final? En primer lugar, el creciente convencimiento de que era inviable retener una única parte de las Filipinas. La posesión de Manila no bastaría para defender los intereses norteamericanos en el área. Una rebelión de los filipinos o la penetración de otras potencias en el resto del archipiélago podrían socavar la presencia americana en aquella ciudad. Por otra parte existía una interdependencia econónica y estratégica entre todas las islas que componían las Filipinas. La partición y separación sería difícil de conseguir y muy poco práctica. Y además, si se quedaban con un sólo área del archipiélago, ¿quíen gobernaría el resto? En estas circunstancias, fue fundamental el temor que el Gobierno norteamericano sintió ante las pretensiones veladas de casi todas las potencias por este ámbito: por una parte, las evidentes ambiciones de estos países en China; por otra los intereses mostrados en participar en un eventual reparto de Filipinas. Ni McKinley ni sus consejeros deseaban un gobierno conjunto de las islas ni querían ver a ninguna otra nación europea ni asiática en ellas si los americanos decidían abandonarlas. Tampoco estaban díspuestos a tolerar una compañía multinacional que las administrara. Finalmente, otro factor que influyó para la anexión de las Filipinas fue la existencia de una opinión pública en los Estados Unidos favorable a la expansión por Extremo Oriente. El Presidente y numerosos miembros de su partido temieron que ir en contra de esta opinión podría hacer peligrar las posibilidades republicanas en las próximas elecciones presidenciales ${ }^{62}$.

Diferentes sectores norteamericanos apoyaban la anexión de las Filipinas. En primer lugar, los comerciantes que operaban en este área desde hace

62 «The sentiment in the United States is almost universal that the people of the Philippines, whatever else is done, must be liberated from Spanish domination. In this sentiment the President fully concurs...) Telegram Mr. Hay to Mr. Day, 28 October 1898, 55th Congress, 3d Session, House of Representatives, Papers relating to the Foreign Relations of the United States, 1898, Washington, Government Printing Office, 1901. Es también interesante a este respecto el cap. 1 «The Decision to take the Philippines» del libro de WELCH, Richard: Response to Imperialism. The United States and the Philippine-American War, 1899-1902, Chapel Hill, The University of North Caroline Press, 1979, págs. 3-23.

Hispania. LVII/2, núm. 196 (1997) 55I-588 
muchos años y que a fuerza de constancia lentamente vieron aumentar sus intereses, primero en el terreno de las importaciones de materias primas filipinas hacia los Estados Unidos, posteriormente en las exportaciones de productos norteamericanos a Filipinas, y, tras la ocupación, en el establecimiento de empresas que se dedicaron a explotar las riquezas de las islas ${ }^{63}$. También

63 El cónsul norteamericano en Manila, al hacer un balance del comercio entre Estados Unidos y Filipinas en 1896, señalaba: 1. Que los Estados Unidos eran el tercer pais en importancia hacia donde se dirigian las exportaciones de Filipinas, después de Gran Bretaña y con un volumen muy similar al de España; 2. Que sin embargo las importaciones de productos norteamericanos a Filipinas eran mucho menores, ocupando el quinto lugar en la lista de naciones importadoras, después de España - que tenia un peso claramente preferencial a gran distancia de cualquier otro pais-, de Gran Bretaña, de Alemania y de Francia. Respecto a los productos intercambiados entre ambos países, Filipinas exportaba a Estados Unidos ábaca, tabaco, copra, azúcar, arroz, café, bambú, cestas, coco, mangos, plátanos, piñas y algodón en rama; en menor medida oro, cobre, hierro y plomo. A su vez, importaba de Estados Unidos productos textiles manufacturados -en especial tejidos de algodón, seda y lana-, aparatos y maquinaria, metales y productos metálicos ya manufacturados, carbón y provisiones varias. Informes Consulares de 1898, Commercial Relations of the United States with Foreign Countries during the year 1898. Issued from the Bureau of Foreign Commerce, Department of State, Washington, Government Printing Office, 1899, vol. I, pág. 140.

En 1898, el mismo consul, Oscar F. Williams, informaba que las exportaciones a Estados Unidos desde el distrito consular de Manila cobraban una creciente importancia. Se componian fundamentalmente de azúcar (el 55 por ciento de las exportaciones de este producto iba a Estados Unidos); ábaca (el volumen de las exportaciones de este producto a Norteamerica se habían incrementado hasta tal punto en el último año, que era un 544 por cien mayor que las exportaciones de esta fibra vegetal a todos los demás países juntos); copra, hojas de tabaco y cigarros también con un volumen importante; y en menor medida café, cuerdas, perlas, indigo, goma y cuero de búfalo. El total de las exportaciones de Filipinas a los Estados Unidos en la década 1887-1897 ascendía a 74.150.284 de dólares, lo cual representaba unos 7.415.028 de dólares por año, aunque de hecho no se repartieron de forma lineal, sino que fueron mayores en los primeros siete años y en 1895, 1896 y 1897 se redujeron a unos 4 millones y medio de dólares, aproximadamente; reducción que probablemente tendría relación tanto con el estado de insurreción que se vivia en las islas, como con las tarifas aduaneras adoptadas por Estados Unidos a partir de 1894. Fuente: Bureau of Statistics, Treasury Department.

Después de la anexión de las islas, la presencia de negocios americanos en Filipinas creció lentamente hasta bien entrada la década de 1920, fecha a partir de la cual experimentó un mayor crecimiento. A pesar de que, entre 1899 y 1902, el comercio entre Filipinas y Estados Unidos se incrementó en 21 millones de dólares, fundamentalmente gracias a la exportación de ábaca, en los primeros años del siglo las empresas que comenzaban a instalarse en las islas, tales como la Philipppine Lumber and Development Company, compañias de ingenieria, plantaciones de azucar impulsadas por A. Burlingame Johnson o una compañía eléctrica que se quiso construir en la ista de Negros, evolucionaron más lentamente de lo planeado. WeLCH: Op. cit., pág. 82. y JeNKINs, Shirley: American Economy Policy towards the Philippines, Stanford, Stanford University Press, 1954, pág.32.

Richard Welch ha discutido el interés económico que podian ofrecer las Filipinas: «Those businessmen who spoke optimistically of the economic opportunities offered by the Philippines usually emphasized the potential of the Filipinos as consumers of American produce, shoes, machinery and textiles. There was much less talk of the Philippines as a market for surplus American capital or as a source of raw materials, and little mention of the Philippines serving as the American equivalent

Hişpania, LVII/2, núm. 196 (1997) 551-588 
subrayaron el interés de estas islas los estrategas y oficiales de la Marina norteamericana que deseaban obtener una base naval desde la que defender los intereses americanos en Oriente. Como ya hemos visto, los políticos expansionistas, partidarios de la participación de Estados Unidos en la política mundial, aprovecharon la ocasión para insistir en la misma dirección. Otro grupo importante fueron las asociaciones religiosas y los misioneros, que solicitaron la protección gubernamental para desarrollar su labor evangelizadora y educadora en las Filipinas ${ }^{64}$. Finalmente, se interesaron por la expansión sobre este archipiélago las compañías que iniciaban el tendido de cables desde San Francisco a las costas asiáticas y cuyo objetivo era controlar las comunicaciones a través del Pacífico ${ }^{65}$.

of Hong Kong. Such business organizations as the New York State Chamber of Commerce were undeniably interested in expanding American trade with China, but only infrequently did they associate this long-term interest with the pacification and economic development of the Philippines. As discussion of our Oriental trade had been sustained throughout the previous without reference to the Philippines, so now it evidently had in the minds of many businessmen no essential relationship to those islands), WELCH, R E.: Response to Imperialism. The United States and the Philippine-American War, 1899-1902, Chapel Hill, The University of North Caroline Press, 1979, pág. 76. Aunque la postura de Welch parece bastante razonable, lo cierto es que una vez que McKinley tomó la decisión de incorporar las Filipinas por motivos esencialmente políticos, - (también se relacionaba con el interés general de potenciar la presencia y los intereses comerciales de Estados Unidos en Extremo Oriente, aunque para ello no era estrictamente necesaria la posesión de Filipinas, hubiera sido posible conseguirlo sin dominar dichas islas)-, los circulos económicos empezaron a subrayar con mayor interés las posibilidades que las Filipinas ofrecían a la economia norteamericana, sobre todo como consumidoras de productos industriales (en especial de textiles, productos metalúrgicos, navieras y empresas constructoras de ferrocarriles). Además, a pesar de las reticencias o del desinterés de algunos sectores, ninguna publicación económica manifestó una oposición directa a la administración de las Filipinas. Por el contrario, y a modo de ejemplo, el New York Journal of Commerce afirmaba: «Give up those islands (las Filipinas) would be an act of inconceivable folly in the face of our imperative future necessities for a basis of naval and military force on the Western shores of the Pacificm.

64 The Presbiterian Banner declaraba en Agosto de 1898 que la prensa religiosa, casi sin excepción, era partidaria de retener las Filipinas como un deber en el interés de la libertad humana y el progreso cristiano, y declaraba que estaban moralmente obligados a convertirse en una potencia asiatica (LAFEBER: $O p$. cit., pág. 214). Welch es mucho más moderado en sus afirmaciones, y aunque señala amplios sectores religiosos que apoyaron la política de McKinley en Filipinas, también resalta las voces de los disidentes, aunque señalando que éstos eran muchos menos (WELCH: Op. cit., págs. 89100). En general, los metodistas, baptistas, presbiterianos, congregacionistas, episcopalistas y otras confesiones minoritarias eran partidarias de desarrollar una nueva misión religiosa en Filipinas; los quáqueros y los unitarios se oponian a la guerra; y los católicos miraban con cierto escepticismo el entusiasmo de los protestantes señalando que los misioneros españoles ya habian evengelizado las islas, aunque en su mayoría acabaron sumándose a los propósitos misioneros de las demás tendencias. La importancia que McKinley concedió a los argumentos religiosos se pueden descifrar de sus palabras: «There was not nothing left for us to do but to take them all (las Filipinas), and to educate the Filipinos, and uplift and civilize and christianize them, and by God's grace to do the very best we could by them as our fellow-men for whom Christ also died) (PRATT: Op. cit., pág. 386).

65 Senate Executive Documents, núm, 24, serial 4417, 57th Congress, First Session, Permission to the Pacific Cable Co. to land cable on Pacific. 
Paralelamente, se produjo la reacción de los círculos anti-imperialistas, que consideraron que la expansión colonial iba en contra de los principios y de las tradiciones más básicas en las que se apoyaban los Estados Unidos; entre ellos políticos como Carniage o Cleveland e intelectuales como Mark Twain. Hubo sectores que se opusieron por motivos menos altruistas, como los cultivadores de azucar; los que temieron la incorporación de nueva población multirracial; o los sindicalistas contrarios a la entrada de mano de obra barata. Sin embargo estas voces se diluyeron ante el clamor popular en favor de la anexión ${ }^{66}$.

En estas circunstancias el Gobierno de McKinley decidió conscientemente, por motivos políticos, económicos, estratégicos e internacionales, anexionarse las Filipinas para defender los intereses americanos en el Pacífico, en China y en el Extremo Oriente. En este sentido se orientaron las negociaciones con España, esbozadas sólo en los meses de Mayo y Junio, apuntadas entre líneas en Julio, más definidas a partir de Agosto y claramente específicadas en el Otoño.

El 26 de Octubre de 1898, convencido ya su entorno político y habiendo obtenido un entusiasta apoyo popular para esta cuestión, McKinley envió las órdenes oportunas a la Comisión de Paz de París para que se hicieran formalmente con todas las Filipinas e intentara conseguir alguno de los archipiélagos menores de la Micronesia ${ }^{67}$. La cuestión se negoció en París en los dos meses siguientes y quedó fijada en el Tratado firmado el 10 de Diciembre de 1898, por el que España cedió a Estados Unidos las Filipinas y las isla de Guam a cambio de una indemnización de veinte millones de dólares. Las Cámaras americanas aprobaron la anexión por un estrecho margen de votos, 57 contra 27, es decir, sólo un voto más de los tres tercios que eran necesarios para la ratificación ${ }^{68}$.

(6) BeISNER, Robert L.: Twelve against Empire. The Anti-imperialists, 1898-1900, New York, McGraw-Hill Book Company, 1968.

67 Telegram from Mr. Hay to Mr. Day, 26 October 1898, «The information which has come to the President since your departure convinces him that the acceptance of the cession of Luzon alone, leaving the rest of the islands subject to Spanish rule, or to be the subject of future contention, can not be justified on political, commercial or humanitarian grounds. The cession must be of the whole archipelago or none. The latter is wholly inadmissible, and the former must be required. The President reaches this conclusion after most thorough consideration of the whole subject, and is deeply sensible of the grave responsabilities it will impose, believing that this course will entail less trouble than any other, and besides will be best subserve the interest of the people ivolved, for whose welfare we can not escapen. 55th Congress, 3d Session, House of Representatives, Papers relating to the Foreign Relations of the United States, 1898, Washington, Government Printing Office, 1901.

68 Entre las últimas interpretaciones que se han hecho de estos acontecimientos, John Dobson resalta: «E] análisis de la dimensión oriental de la guerra hispano-norteamericana demuestra que McKinley fueran cuales fuesen sus ideas previas, actuó como un expansionista. Se mostró sensible a los argumentos esgrimidos por los partidarios de la expansión. Creó los mecanismos necesarios para desartollar una política expansionista. Aprovechó la guerra con España para hacerse con territorios en el Pacífico. Las acciones emprendidas y las decisiones tomadas en este proceso revelan una clara intención de introducirse en el Extremo Oriente de manera definitiva, y no sólo de forma

Hispania, LVI12, núm. 196 (1997) 551-588 
Los resultados de las operaciones en el Pacífico inspiraron el siguiente informe del embajador de Estados Unidos en Francia, Horace Porter:

\begin{abstract}
Mis colegas europeos me han expresado su opinión de que hemos hecho en tres meses lo que las grandes potencias de Europa han estado intentando hacer en vano en los últimos cien años: hemos obtenido una cadena de islas en el Pacifico que garantizan nuestras comunicaciones; hemos restaurado la seguridad en las Filipinas y capturado su comercio; hemos conseguido el trazado de un cable bajo nuestro control a lo largo de todo este océano; hemos ocupado Manila, sólo a dos dias de distancia de la costa china, lo cual nos posibilita proteger nuestros intereses en el Extremo Oriente, sin tener que sufrir las amenazas de la armada china o rusa en nuestra retaguardia ${ }^{69}$.
\end{abstract}

\title{
CONCLUSIONES
}

La expansión por el Pacífico, consolidada durante la guerra hispano-norteamericana de 1898, implicó para los Estados Unidos una nueva orientación en su acción exterior. Supuso el desarrollo de una política mundial, su inclusión en el grupo de potencias que fijaban las directrices de la vida internacional, en la cual, y desde entonces, serían un interlocutor permanente. Significó también su irreversible implicación fuera de las fronteras continentales. Condujo al país a la construcción de un imperio colonial ultramarino. El Pacífico marcó su devenir de nación a imperio.

Para España el proceso fue obviamente a la inversa. La pérdida de sus colonias en el Caribe y en el Pacífico tuvo también una significación internacional relevante. Se tradujo en una quiebra definitiva en la posición que había ocupado hasta ese momento en la escena mundial. El consecuente y definitivo recogimiento hacia un ámbito territorial mucho más limitado. A partir de

coyuntural durante la guerra, ni en un espacio necesariamente limitado a Manila.» Dosson, J.: Reticent Expansionism. The Foreign Policy of Willian McKinley, Pittsburgh, Pennsylvania, Duquesne University Press, 1988.

Opinión no muy diferente de la que sostiene John Offner: «The American government took different stances toward the Atlantic and the Pacific. The McKinley administration never attacked Spanish colonies in the eastern Atlantic or Mediterranean Seas. It steered clear of the Canary Islands, Fernando Po, Tangiers, Ceuta, and the Balearic Islands. In effect, the Atlantic Ocean still existed as a barrier, with Europe held at arm's length from Western Hemisphere and with American restraint exhibited toward North Africa and the Mediterranean. The Pacific Ocean was different. Dewey's victory was followed by an army expedition to the Philippines and an assault on Manila. The Americans took Guam and annexed the Hawaiian Islands. Clearly the Far East was more attractive. The question was not one of taking Pacific naval bases and coaling stations but of determining how much to acquire. McKinley's cabinet contained a spectrum of views, but only one in nine wanted nothing. Overwheimingly, the McKinley administration favored expansionm. OfFNER, J.: An Unwanted War. The Diplomacy of the United States and Spain over Cuba, /895-1898, Chapel Hill, The University of North Carolina Press, 1992, pág. 223.

69 Citado por MCCormicK, Thomas: The China Market, Chicago, 1967, pág. 224.

Hispania, LVII/2, núm. 196 (1997) 551-588 
1898 la importancia internacional de España vendría marcada por su estratégica posición. Frontera meridional de Europa, dueña de unos significativos enclaves en el eje Baleares-Marruecos-Canarias. Desde esta posición, el Norte de Africa cobraría en las décadas siguientes un nuevo interés en su acción exterior.

1898 conllevó también para España un replanteamiento de la política internacional seguida en las últimas décadas: la pérdida de las colonias; la sensación de haberse visto aislados y sin apoyos exteriores de ningún tipo; el temor vivido ante la incertidumbre de los límites que iba a tener el reparto de territorios que estaban haciendo las grandes potencias a su costa, etc, obligaron a los políticos españoles a replantearse los principios y la orientación de su política exterior. A partir de 1898 el objetivo sería la búsqueda de una garantía exterior que asegurara la inviolabilidad del territorio, afianzar los límites y las posesiones extrapeninsulares, potenciar la capacidad defensiva y en última instancia la consecución de unos acuerdos internacionales. Todo ello implicó un giro hacia Francia y Gran Bretaña, que culminaría en los acuerdos de 1904-1907. Esta nueva orientación hacia el área de influencia franco-británica sería una constante mantenida hasta mediados del siglo $\mathrm{xX}$, en que la antigua potencia enemiga - Estados Unidos - se convirtió en vale. dora internacional del régimen de Franco. Curiosa paradoja histórica, por la cual un sistema político que se autodefinía como ultranacionalista vino a consumar una fuerte dependencia internacional frente a quien pusiera la puntilla final en el proceso de declinación española de imperio a nación. 